
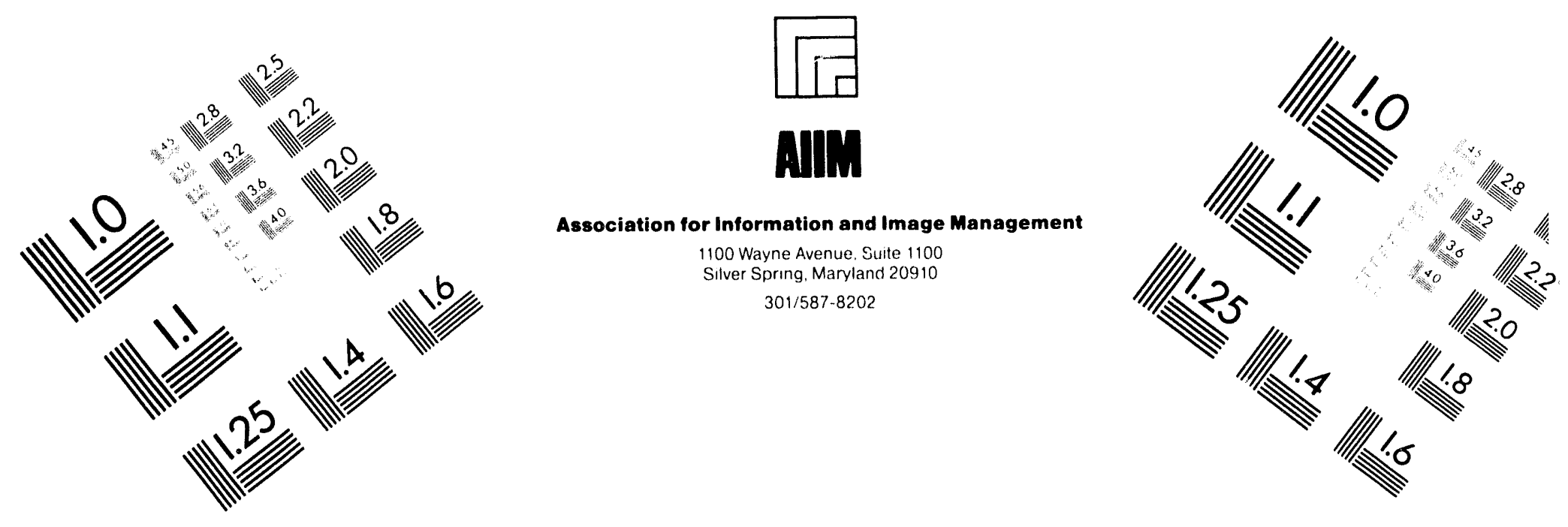

Centimeter

|

Inches
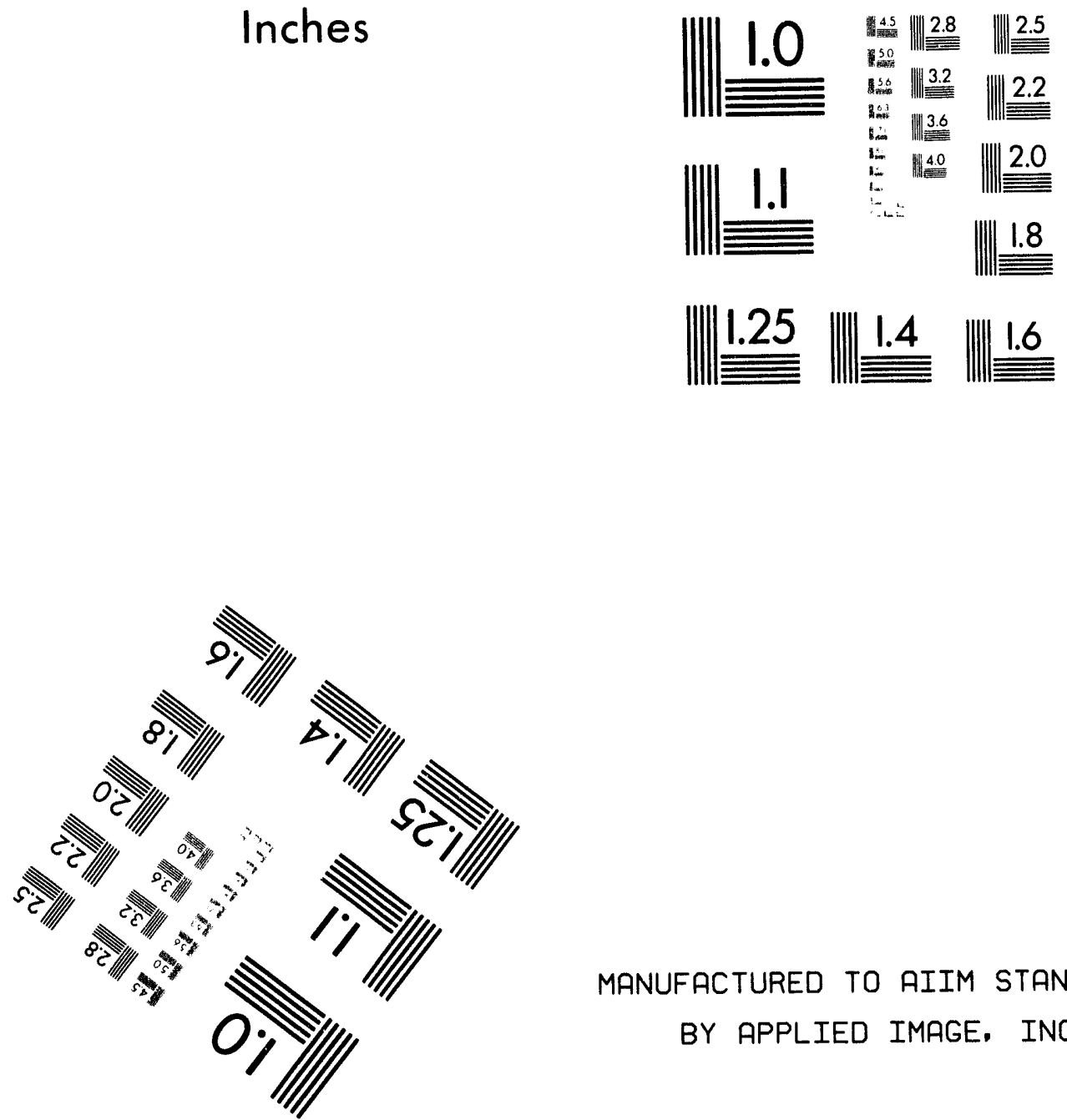

MANUFACTURED TO AIIM STANDARDS

BY APPLIED IMAGE, INC.

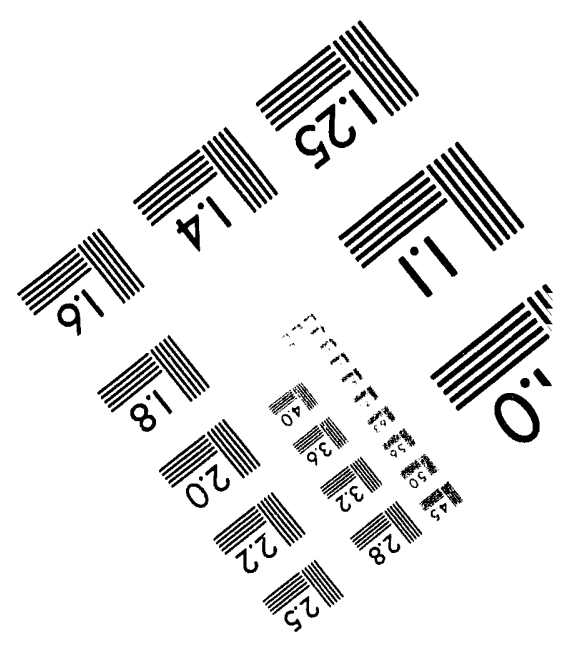



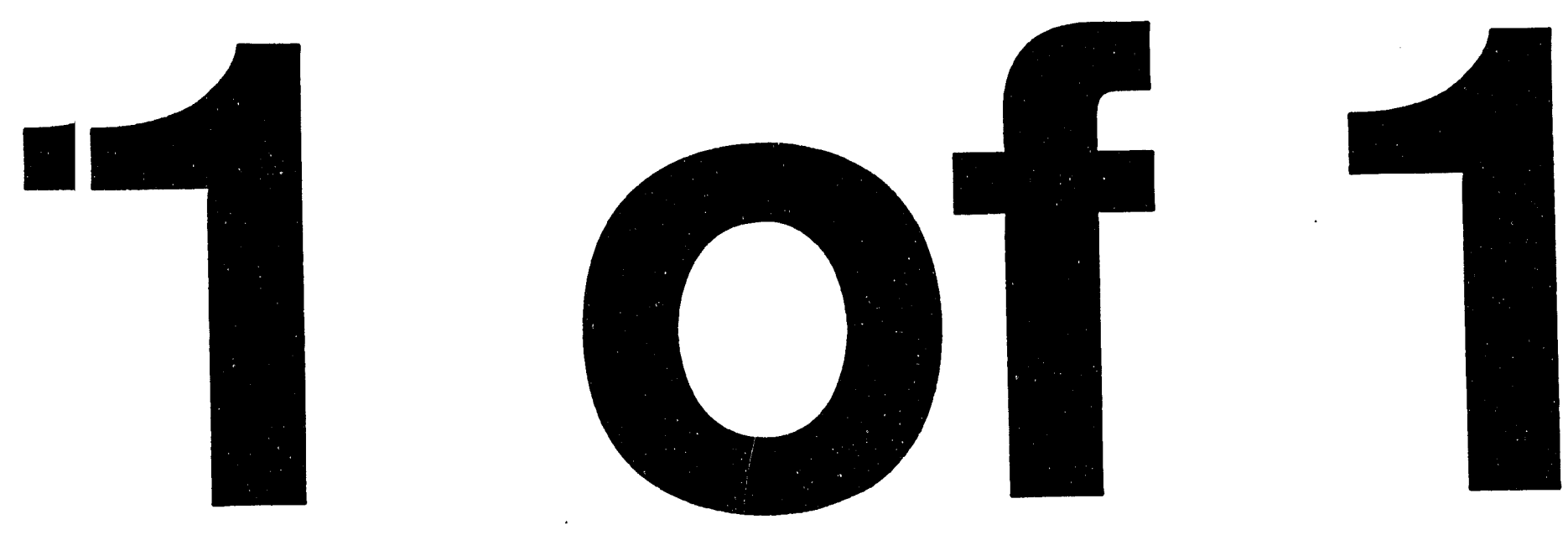


\section{Test Plan for Preparing the Rapid Transuranic Monitoring Laboratory for Field Deployment}

C. V. Mclsaac

C. W. Sill

R. J. Gehrke

E. W. Killian

K. D. Watts

Published April 1994

Idaho National Engineering Laboratory

EG\&G Idaho, Inc.

Idaho Falls, Idaho 83415

Prepared for the

U.S. Department of Energy

Office of Environmental Restoration and Waste Management Under DOE Idaho Operations Office

Contract DE-AC07-761D01570 


\section{Test Plan for Preparing the Rapid Transuranic Monitoring Laboratory for Field Deployment}

EGG-WTD-11208

Prepared by

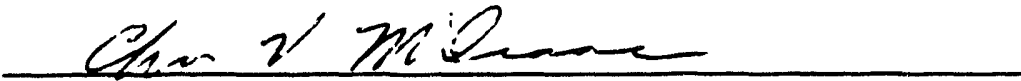

C. V. McIsaac, Scientific Specialist

$$
4-18-94
$$

Date

Radiation Measurements and Development

Reviewed by

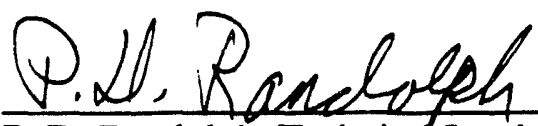

P. D. Randolph, Technical Leader

Radiation Measurements and Development

Approved by

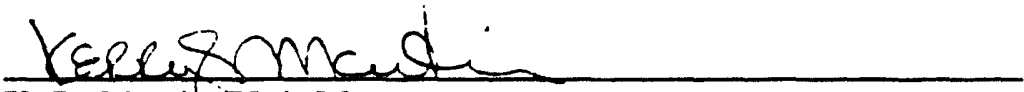

K. L. Martin, Unit Manager

Radiation Measurements and Development $\frac{4-2 s-94}{\text { Date }}$ 


\begin{abstract}
This plan describes experimental work that will be performed during fiscal year 1994 to prepare the Rapid Transuranic Monitoring Laboratory (RTML) for routine field use by U.S. Department of Energy (DOE) Environmental Restoration and Waste Management programs. The RTML is a mobile, field-deployable laboratory developed at the Idaho National Engineering Laboratory (INEL) that provides a rapid, cost-effective means of characterizing and monitoring radioactive waste remediation sites for low-level radioactive contaminants. Analytical instruments currently installed in the RTML include an extended-range, germanium photon analysis spectrometer with an automatic sample changer; two, large-area, ionization chamber alpha spectrometers; and four alpha continuous air monitors. The RTML was field tested at the INEL during June 1993 in conjunction with the Buried Waste Integrated Demonstration's remote retrieval demonstration. The major tasks described in this test plan are to (a) evaluate the beta detectors for use in screening soil samples for ${ }^{90} \mathrm{Sr}$, (b) upgrade the alpha spectral analysis software programs, and (c) upgrade the photon spectral analysis software programs.
\end{abstract}




\section{SUMMARY}

This test plan describes objectives, instrumentation, and experimental procedures used to prepare the Rapid Transuranic Monitoring Laboratory (RTML) for routine field deployment by the U.S. Department of Energy (DOE) Environmental Restoration and Waste Management programs. The RTML is a mobile laboratory developed at the Idaho National Engineering Laboratory (INEL) for use in characterizing low-level radiological source terms at buried radioactive waste remediation sites. Analytical instruments now installed in the RTML include an extended-range, photon analysis spectrometer equipped with an automatic sample changer; two, large-area, ionization chamber alpha spectrometers; and four, remotely operated, alpha continuous air monitors (CAMs). Detailed operating procedures for the RTML are presented in Operating Procedures for Rapid Transuranic Monitoring Laboratory. ${ }^{1}$ The RTML was field tested during June 1993 at the Cold Test Pit (CTP) in the Radioactive Waste Management Complex (RWMC) at the INEL in conjunction with the Buried Waste Integrated Demonstration's (BWID's) remote retrieval demonstration. Results of the field test are presented in Field Test of the Rapid Transuranic Monitoring Laboratory. ${ }^{2}$

During past years radioactive waste contaminated with transuranic (TRU) elements was stored in shallow pits and trenches at a number of DOE facilities throughout the DOE complex. Retrieval of this waste is one of the remediation options now being considered. It is anticipated that waste containers have degraded over the years and a significant fraction of the backfill soil in these pits and trenches is now contaminated with TRU elements and long-lived fission and activation products. Therefore, during the waste retrieval effort, the air, soil, and deposited dusts will have to be monitored continuously for radioactive contaminants to protect personnel involved in the retrieval operations and to provide data needed to assess and control the spread of radioactive contamination. Monitoring of radioactive contaminants during retrieval is required by DOE Order 5480.11, "Radiation Protection for Occupational Workers."

From fiscal year (FY) 1990 through FY-92, a number of promising measurement methods and systems were evaluated for possible use in monitoring TRU concentrations in ambient air and in soil, smear, and dust samples collected during remediation of buried radioactive waste. These evaluations demonstrated that the alpha CAM used at Argonne National Laboratory-West (ANL-W) had a sensitivity for airborne ${ }^{239} \mathrm{Pu}$ at 10 to 20 times better than the sensitivities of four commercial alpha CAMs that were also tested. Six of the ANL-W alpha CAMs were fabricated during FY-92, and four of them are now installed in the alpha CAM sampling stations that are operated remotely from the RTML. Direct alpha spectrometry with a large-area ionization chamber and photon spectrometry with a high-resolution, n-type, extended-range germanium spectrometer were shown to be rapid, sensitive methods fo: the measurement of TRU isotopes on smears and in soil and dust samples. The two analysis techniques do not require elaborate sample preparation or time-consuming chemical separations; soil samples for the photon spectrometer are dried and sieved prior to analysis, while soil samples for the ionization chambers are dried, sieved, and ground in $30 \%$ ethanol prior to analysis. Smears and filters are analyzed directly without any sample preparation.

The RTML consists of two separate mobile trailers that can be powered from either plant power or from portable electric generators. One trailer, $2.4-\mathrm{m}$ wide $\times 7.3-\mathrm{m}$ long $(8 \times 24 \mathrm{ft})$, houses the sample preparation laboratory that is equipped with a fume hood; fume hood, high efficiency particulate air (HEPA) filter; gravity-flow drying oven; sieving equipment; analytical balances; compressed air cylinders; hotplates; and a supply of sample planchets and containers. Samples are received and prepared for analysis in this trailer. If plant power is unavailable, power to the sample preparation trailer is supplied from a $50 \mathrm{~kW}$ or larger generator. The second trailer, $2.4-\mathrm{m}$ wide $\times$ 14.6 - $\mathrm{m}$ long $(8 \times 48 \mathrm{ft})$, houses the analytical instruments and computer used to acquire, analyze, and 
archive photon and alpha spectra from soil, smear, and air filter samples. The latter trailer also houses the computer terminal used to remotely control the operation of the four field-deployable alpha CAMs. If plant power is unavailable, power to the analysis trailer is supplied from a generator rated at $30 \mathrm{~kW}$ or more, and power to the alpha CAMs is supplied from a $5 \mathrm{~kW}$ or larger generator. No generators have been purchased for the RTML. The three generators used during the June 1993 demonstration at the CTP were all leased.

Analytical instruments now installed in the RTML will, in principle, allow the determination of the concentrations of all alpha and photon-emitting radionuclides in the ambient air and in discrete soil and dust samples. Contaminants currently targeted by the RTML include ${ }^{252} \mathrm{Cf},{ }^{242} \mathrm{Cm},{ }^{243} \mathrm{Cm}$, ${ }^{244} \mathrm{Cm},{ }^{241} \mathrm{Am},{ }^{243} \mathrm{Am},{ }^{236} \mathrm{Pu},{ }^{238} \mathrm{Pu},{ }^{239} \mathrm{Pu},{ }^{240} \mathrm{Pu},{ }^{242} \mathrm{Pu},{ }^{237} \mathrm{~Np},{ }^{232} \mathrm{U},{ }^{233} \mathrm{U},{ }^{234} \mathrm{U},{ }^{235} \mathrm{U},{ }^{236} \mathrm{U},{ }^{238} \mathrm{U}$, ${ }^{228} \mathrm{Th},{ }^{230} \mathrm{Th},{ }^{232} \mathrm{Th},{ }^{226} \mathrm{Ra},{ }^{154} \mathrm{Eu},{ }^{137} \mathrm{Cs}$, and ${ }^{60} \mathrm{Co}$. Because 14.4 -year ${ }^{241} \mathrm{Pu}$ decays by beta emission, ${ }^{241} \mathrm{Pu}$ is one TRU isotope of interest that is not currently targeted. Currently, the RTML is not capable of analyzing samples for long-lived beta-emitting fission and activation products such as 5,730 -year ${ }^{14} \mathrm{C}, 3.01 \times 10^{5}$-year ${ }^{36} \mathrm{Cl}, 100$-year ${ }^{63} \mathrm{Ni}$, and 28.5 -year ${ }^{90} \mathrm{Sr}$.

Traditional chemical methods used to determine ${ }^{90} \mathrm{Sr}$ in solid samples are quite laborious and time consuming. Analytical methods that might be used to screen samples for ${ }^{90} \mathrm{Sr}$ that do not require elaborate sample pretreatment and chemical separation will be investigated, and selected methods will be evaluated experimentally. Analytical instruments that have been identified for evaluation include the large-area beta detector ${ }^{3}$ recently developed at Pacific Northwest Laboratories and a large-area, scintillation beta counter now under development at the INEL.

Previous work has shown that, in the case of spectra collected using the alpha CAMs, the background under the ${ }^{239} \mathrm{Pu}$ and ${ }^{241} \mathrm{Am}$ alpha peaks is strongly affected by the concentration of dust in the air being sampled. Similarly, in the case of alpha spectra collected using the ionization chambers, the background and counting efficiency in the region of the TRU alpha peaks are affected by irregularities in the distribution of the sample over the sample pan or membrane filter. Alpha spectrum analysis techniques that have been developed and adopted by the RTML will be refined and tested experimentally to determine the adequacy of the background correction methods over a range of experimental conditions. Methods of spraying soil suspensions on steel sample pans will be improved to decrease losses and increase spectral resolution. Additional experimental work will be done to determine which filters should be used to collect smear and air filter samples for analysis with the large-area, ionization chamber alpha spectrometers. Based on the results of these evaluations, existing RTML alpha spectrum analysis software will be modified to improve analysis reliability and sensitivity.

The field test ${ }^{2}$ showed that the statistical calculations now performed by the LXRAY spectrum analysis code developed for the photon spectrometer are incomplete and underestimate the uncertainty in the reported plutonium and ${ }^{241} \mathrm{Am}$ concentrations. The $\mathrm{x}$-ray spectrum analysis software will be upgraded so that uncertainties are calculated including contributions from the finite size of the zero and gain shifts. The field test also revealed a systematic error in the ${ }^{239} \mathrm{Pu}$ activity concentrations measured with the photon spectrometer. The measured ${ }^{239} \mathrm{Pu}$ concentrations in blind soil standards were, on the average, biased low by about $16 \%$. The source of this bias will be identified and corrected. The upgrade of the LXRAY program will also incorporate changes that will permit the background scaling factor to vary so as to search for the best background value. An off-line spectrum analysis capability will also be developed to permit the reanalysis of spectral data using different components and backgrounds. In addition, modifications to the LXRAY program will be investigated that might allow the LXRAY program to use the VAXGAP gamma-ray results for ${ }^{241} \mathrm{Am}$ to calculate the ${ }^{241} \mathrm{Am}$ component of the combined ${ }^{239} \mathrm{Pu} /{ }^{241} \mathrm{Am}$ L-shell $\mathrm{x}$-ray peaks. 


\section{CONTENTS}

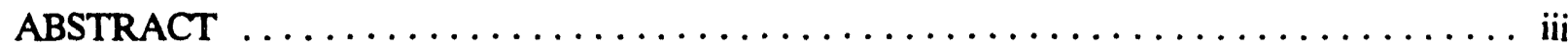

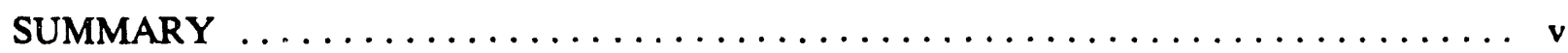

ACRONYMS $\ldots \ldots \ldots \ldots \ldots \ldots \ldots \ldots \ldots \ldots \ldots \ldots \ldots \ldots \ldots \ldots \ldots \ldots \ldots \ldots \ldots$

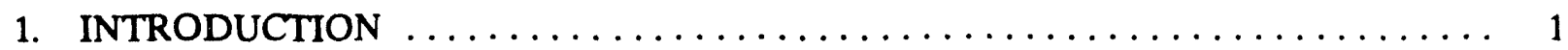

1.1 Technology Description and Background $\ldots \ldots \ldots \ldots \ldots \ldots \ldots \ldots \ldots \ldots$

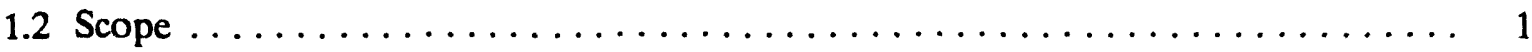

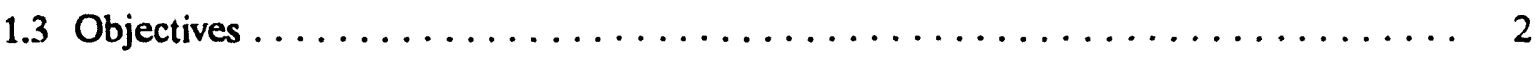

1.4 Technology Agreement $\ldots \ldots \ldots \ldots \ldots \ldots \ldots \ldots \ldots \ldots \ldots \ldots \ldots \ldots \ldots$

2. ORGANIZATION AND RESPONSIBILITIES $\ldots \ldots \ldots \ldots \ldots \ldots \ldots \ldots \ldots$

2.1 Organizational Affiliations and Responsibilities $\ldots \ldots \ldots \ldots \ldots \ldots \ldots \ldots \ldots$

2.2 Personnel Support Requirements $\ldots \ldots \ldots \ldots \ldots \ldots \ldots \ldots \ldots \ldots \ldots \ldots$

3. DESCRIPTION OF TEST $\ldots \ldots \ldots \ldots \ldots \ldots \ldots \ldots \ldots \ldots \ldots \ldots \ldots \ldots \ldots \ldots$

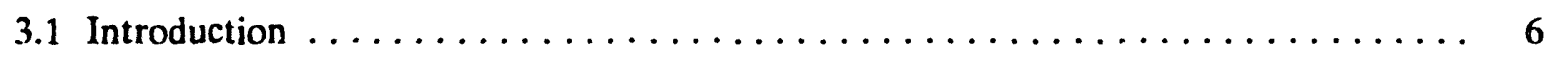

3.1.1 Evaluate Beta Detectors ....................... 7

3.1.2 Upgrade Photon Analysis Spectrometer Software $\ldots \ldots \ldots \ldots \ldots \ldots \ldots$

3.1.3 Upgrade Alpha Spectral Analysis Software ................ 10

3.2 Location, Duration, and Schedule of Tests $\ldots \ldots \ldots \ldots \ldots \ldots \ldots \ldots \ldots$

4. TASKS AND SEQUENCE OF ACTIVITIES $\ldots \ldots \ldots \ldots \ldots \ldots \ldots \ldots \ldots \ldots$

5. SAMPLING AND DATA COLLECTION $\ldots \ldots \ldots \ldots \ldots \ldots \ldots \ldots \ldots \ldots \ldots \ldots \ldots \ldots$

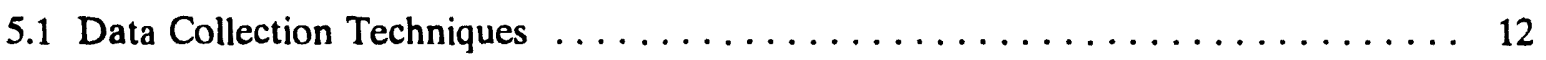

5.1 .1 Beta Detectors . . . . . . . . . . . . . . . 12

5.1.2 Large-area Ionization Chamber Alpha Spectrometers .............. 13

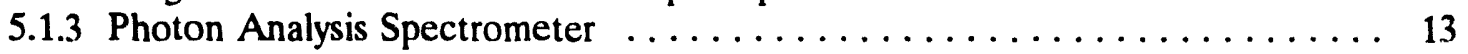

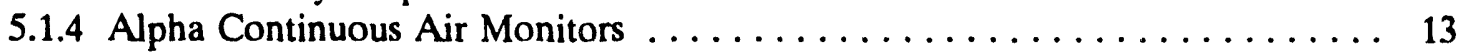

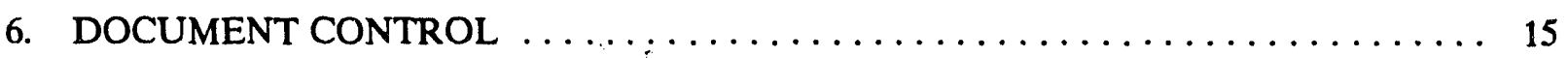

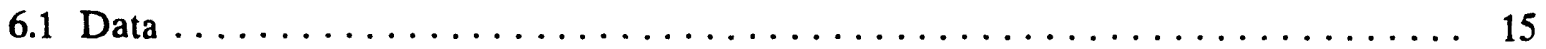




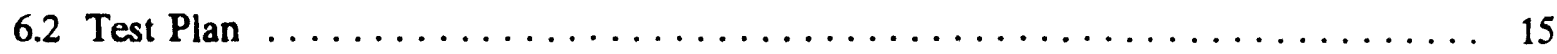

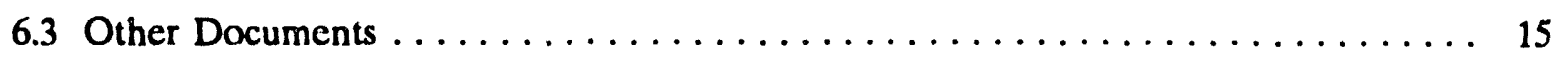

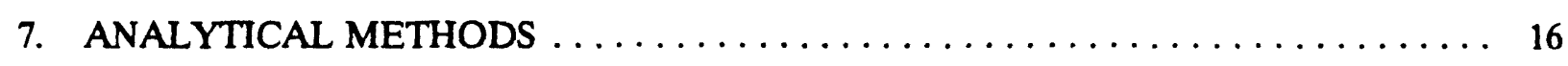

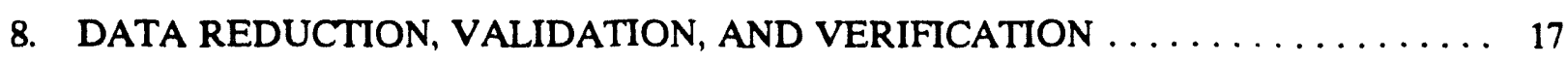

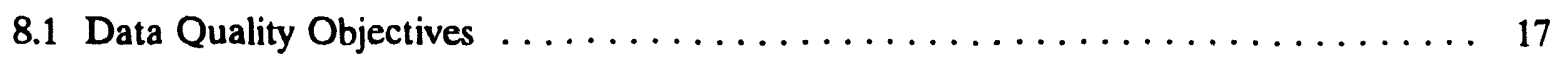

8.2 Data Reduction Scheme $\ldots \ldots \ldots \ldots \ldots \ldots \ldots \ldots \ldots \ldots \ldots \ldots \ldots \ldots$

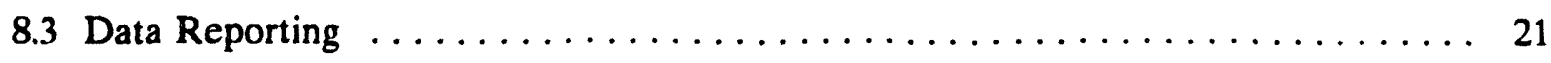

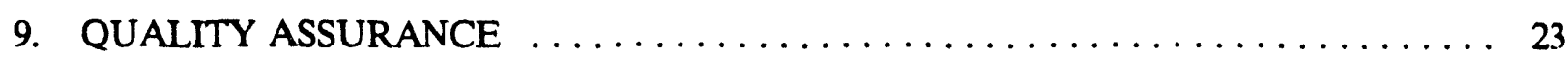

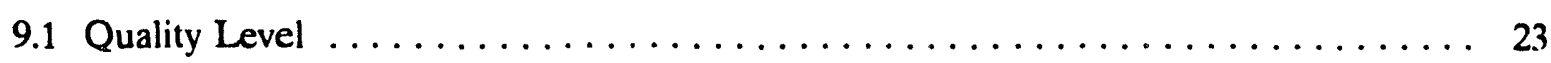

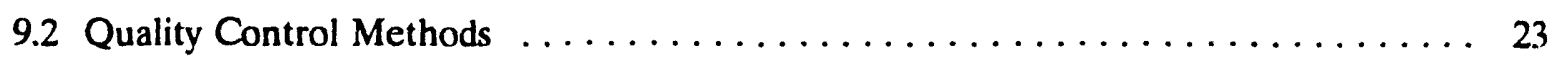

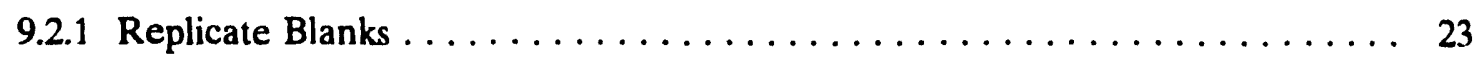

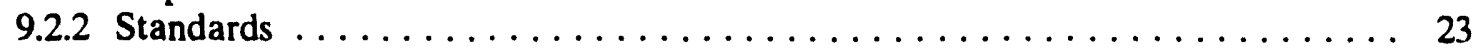

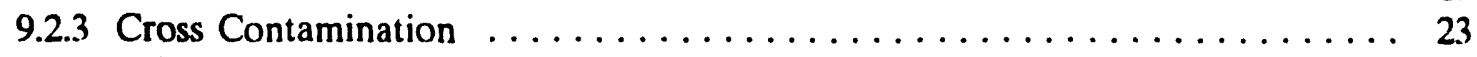

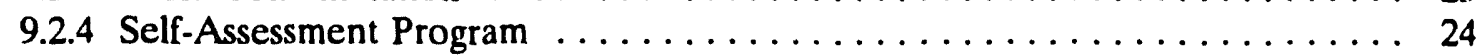

9.3 Routine Procedures to Achieve Precision and Accuracy ............. 24

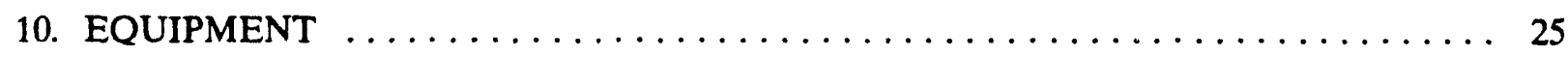

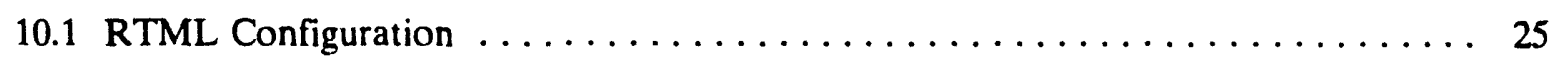

10.2 Sample Preparation Equipment $\ldots \ldots \ldots \ldots \ldots \ldots \ldots \ldots \ldots \ldots \ldots \ldots \ldots \ldots \ldots$

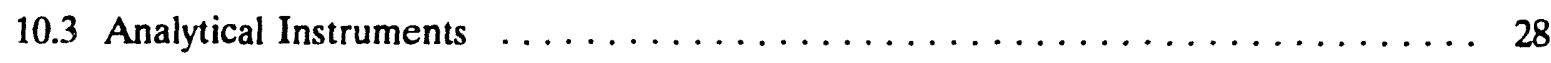

10.3.1 Beta Detectors . . . . . . . . . . . . . . . . . . . 28

10.3.2 Large-area Ionization Chamber Alpha Spectrometers . . . . . . . . . 28

10.3.3 Photon Analysis Spectrometer System . . . . . . . . . . . . . . . 28

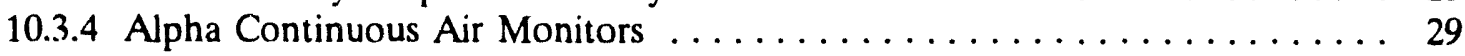

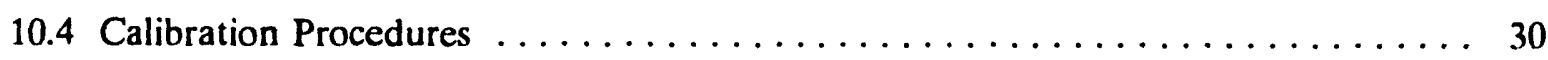

10.4.1 Beta Detectors . . . . . . . . . . . . . . . . . . . 30

10.4.2 Large-area Ionization Chamber Alpha Spectrometers . . . . . . . . . 30

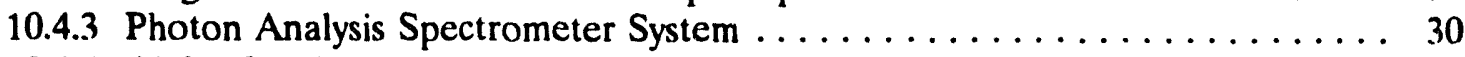

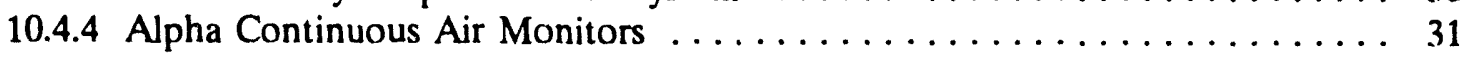

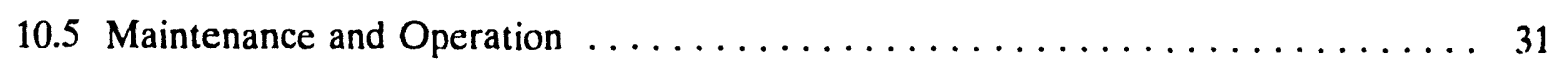

10.6 Sensitivity to Environmental Conditions $\ldots \ldots \ldots \ldots \ldots \ldots \ldots \ldots \ldots \ldots \ldots \ldots \ldots$ 
11. SUPPLIES, UTILITIES, AND FACILITIES $\ldots \ldots \ldots \ldots \ldots \ldots \ldots \ldots \ldots \ldots \ldots$

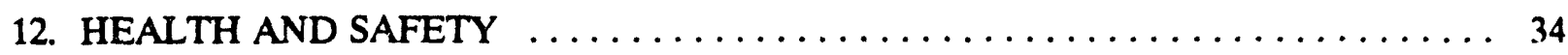

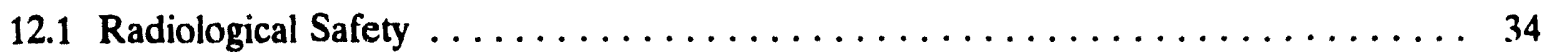

12.2 Laboratory Safety . . . . . . . . . . . . . . 35

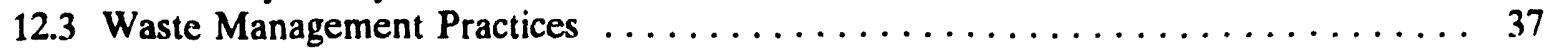

13. RESIDUALS MANAGEMENT $\ldots \ldots \ldots \ldots \ldots \ldots \ldots \ldots \ldots \ldots \ldots \ldots \ldots \ldots \ldots$

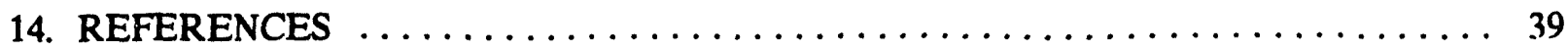

Appendix A-Full-scale Operation Estimates $\ldots \ldots \ldots \ldots \ldots \ldots \ldots \ldots \ldots \ldots \ldots \ldots \ldots \ldots$

Appendix B-CERCLA Criteria $\ldots \ldots \ldots \ldots \ldots \ldots \ldots \ldots \ldots \ldots \ldots \ldots \ldots \ldots \ldots \ldots \ldots \ldots$

\section{FIGURES}

1. Key personnel in RTML development and testing $\ldots \ldots \ldots \ldots \ldots \ldots \ldots \ldots$

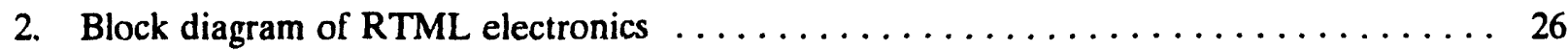

\section{TABLES}

1. Summary of beta decay data for ${ }^{90} \mathrm{Sr},{ }^{90} \mathrm{Y}$, long-lived fission and activation products, and

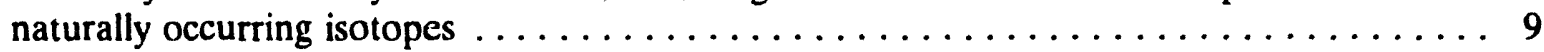

2. Activity/milestone summary for FY-94 $\ldots \ldots \ldots \ldots \ldots \ldots \ldots \ldots \ldots \ldots \ldots$ 


\section{ACRONYMS}

\begin{tabular}{|c|c|}
\hline ADC & Analog-to-digital converter \\
\hline AIM & Acquisition interface module \\
\hline ANL-W & Argonne National Laboratory-West \\
\hline BWID & Buried Waste Integrated Demonstration \\
\hline CTP & Cold Test Pit \\
\hline CERCLA & Comprehensive Environmental Response, Compensation, and Liability Act \\
\hline CAM & Continuous air monitor \\
\hline DAC & Derived air concentration \\
\hline DOE & U.S. Department of Energy \\
\hline ER\&WM & Environmental Restoration and Waste Management \\
\hline FY & Fiscal year \\
\hline HEPA & High efficiency particulate air \\
\hline HP & Health physics \\
\hline INEL & Idaho National Engineering Laboratory \\
\hline LABD & Large-area beta detector \\
\hline LLD & Lower limit of detection \\
\hline LN & Liquid nitrogen \\
\hline NIM & Nuclear instrument module \\
\hline N\&RP & Nuclear and Radiological Physics \\
\hline NIST & National Institute of Standards and Technology \\
\hline PNL & Pacific Northwest Laboratories \\
\hline PI & Principal investigator \\
\hline PIPS & Passivated implanted planar silicon \\
\hline RADCON & Radiological control \\
\hline
\end{tabular}


RM\&D Radiation Measurements and Development

RML Radiation Measurements Laboratory

ROI Region of interest

RTML Rapid Transuranic Monitoring Laboratory

RWMC Radioactive Waste Management Complex

TRA Test Reactor Area

TRU Transuranic 


\section{Test Plan for Preparing the Rapid Transuranic Monitoring Laboratory for Field Deployment}

\section{INTRODUCTION}

This test plan describes the objectives, instrumentation, and experimental procedures needed to prepare the Rapid Transuranic Monitoring Laboratory (RTML) for routine field use. The analytical technologies that will be developed and tested experimentally include (a) beta detectors. (b) photon analysis spectrometer system. (c) large-area, ionization chamber alpha spectrometers, and (d) alpha continuous air monitors (CAMs).

\subsection{Technology Description and Background}

During the spring of 1993, a tractor trailer previously used for a U.S. Department of Energy (DOE) environmental survey program was remodeled to serve as the RTML analysis laboratory. Two, large-area, ionization chamber alpha spectrometers, an extended-range germanium photon spectrometer with an automatic sample changer, a VAX 4000 model 100 computer, four computer terminals with monitors, and a laser printer were installed in the trailer during March and April 1993. The four Ipha CAMs fabricated during fiscal year (FY) 1992 were integrated into the RTML during this same time frame. Software written during FY-92 to operate the three measurement systems and display, analyze, and archive measured alpha and photon spectral data was installed on the VAX 4000 during March 1993. A sample preparation trailer equipped with a fume hood was procured in June 1993. During June 1993, the RTML was tested at the Test Reactor Area (TRA), while power to the two trailers and alpha CAMs was supplied from portable generators. Soil samples that had been collected from the Cold Test Pit (CTP) in the Radioactive Waste Management Complex (RWMC) at the INEL were analyzed during this initial test conducted at TRA. The RTML sample preparation and analysis trailers and the four alpha CAMs were then moved to a location adjacent to the CTP and field tested during June 1993 in conjunction with the Buried Waste Integrated Demonstration's (BWID's) remote retrieval demonstration. Results of the field test are presented in Field Test of the Rapid Transuranic Monitoring Laboratory. ${ }^{2}$

\subsection{Scope}

The scope of this test plan is limited to laboratory evaluations of analytical instruments already installed in the RTML and beta detectors that will be borrowed or developed during FY-94. The purpose of this work is to prepare the RTML for field deployment. 


\subsection{Objectives}

The general objectives identified in this test plan include (a) selecting, testing, and installing a beta detector system for use in measuring ${ }^{90} \mathrm{Sr}$ in soil samples, (b) optimizing the existing RTML analytical equipment, and (c) upgrading the existing photon and alpha spectral analysis software.

The primary objectives include

- Develop nonchemical analytical techniques that could be used to screen soil samples for ${ }^{90} \mathrm{Sr}$ at concentrations below $100 \mathrm{pCi} / \mathrm{g}$ and experimentally evaluate the most promising techniques.

- Develop spectral analysis techniques and software for the large-area ionization chamber ior automatic quantitative analysis of soil, smear, and air filter samples.

- Develop an improved method of estimating background counts in alpha peaks of transuranic (TRU) isotopes in spectra measured with the alpha CAMs and ionization chambers.

- Develop spectrum analysis software for the alpha CAMs that will automatically calculate the average airborne TRU concentration during a given sampling interval.

- Modify the equations used to calculate uncertainties in airborne TRU concentrations measured with the alpha CAMs to include all uncertainty components.

- Modify the LXRAY program uscd to analyze x-ray spectra measured with the photon analysis spectrometer system so that uncertainties in TRU concentrations are calculated using realistic estimates of all uncertainty components.

- Investigate the source of an apparent bias in ${ }^{239} \mathrm{Pu}$ concentrations measured with the photon analysis spectrometer system.

- Write and implement software to calculate corrections for cascade coincidence summing in gamma-ray spectra.

- Develop methods to decontaminate sample plates analyzed in the large-area ionization chambers and identify disposable materials that could be used in lieu of stainless steel plates.

The secondary objectives include

- Improve the method used to prepare soil samples for analysis with the large-area ionization chamber alpha spectrometers. 
- Determine the physical yield of the soil preparation method developed for the large-area. ionization chamber alpha spectrometers.

- Determine the best filter to use with the high-volume air samplers for analysis with the largearea ionization chambers.

- Measure the counting efficiencies of the large-area ionization chambers for high-volume air filter samples.

- Develop software that will allow recalling and reanalyzing alpha CAM spectra previously stored in computer memory.

- Upgrade the LXRAY program to incorporate changes that will permit the background scaling factor to vary so as to search for the best background value.

- Develop an off-line spectrum analysis capability to permit reanalysis of photon spectrometer spectral data using different components and backgrounds.

Data quality objectives of the FY-94 work focus primarily on determining the sensitivity of each measurement system for detection of TRU and/or fission product radionuclides using counting times of 30 minutes or less. Technical performance goals include producing field-deployable measurement systems with the following sensitivities: (a) an alpha CAM system with a sensitivity for airborne TRU isotopes that is superior to the sensitivity required by DOE Order 5480.11 , (b) large-area, ionization chamber alpha spectrometers capable of analyzing soil samples in $\mathbf{3 0}$ minutes or less with a lower limit of detection (LLD) concentration of $50 \mathrm{pCi} / \mathrm{g}$ for TRU isotopes and air samples with an LLD of 0.1 derived air concentration (DAC)-h, and (c) a photon analysis spectrometer capable of analyzing soil samples in 30 minutes or less with LLDs of $50 \mathrm{pCi} / \mathrm{g}$ for plutonium, $1 \mathrm{pCi} / \mathrm{g}$ for ${ }^{241} \mathrm{Am}, 4 \mathrm{pCi} / \mathrm{g}$ for ${ }^{60} \mathrm{Co}$, and $3 \mathrm{pCi} / \mathrm{g}$ for ${ }^{137} \mathrm{Cs}$. The technical performance goals also include identifying, and possibly developing, a field-deployable beta counter capable of screening soil samples for ${ }^{90} \mathrm{Sr}$ at concentrations below $100 \mathrm{pCi} / \mathrm{g}$.

\subsection{Technology Agreement}

The Radiation Measurements and Development (RM\&D) and Nuclear and Radiological Physics (N\&RP) Units of EG\&G Idaho, Inc. are participating in the BWID program and developing a mobile laboratory that provides a rapid, cost-effective means of monitoring air for TRU contaminants and analyzing soil, air, water, and smear samples for TRU isotopes and fission and activation products. This project is a continuation of the FY-93 Technical Task Plan ID1-2-12-10, "BWID Contamination Control" and covers work needed to prepare the RTML for routine use by DOE's Environmental Restoration and Waste Management (ER\&WM) programs. 


\section{ORGANIZATION AND RESPONSIBILITIES}

\subsection{Organizational Affiliations and Responsibilities}

The organizational affiliations and responsibilities of the key personnel involved in the development and testing of RTML analytical instrumentation are shown in Figure 1. Personnel from the RM\&D and N\&RP Units of EG\&G Idaho, Inc. will perform all experimental work.

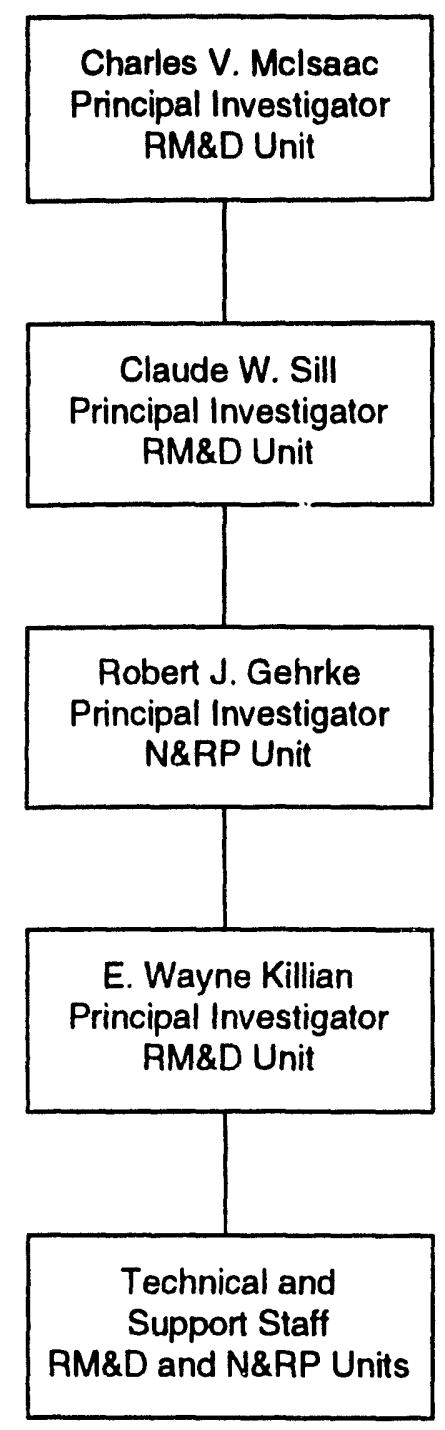

Figure 1. Key personnel in RMTL development and testing. 
Responsibilities of the key personnel are described below.

- Charles V. McIsaac, principal investigator (PI), is responsible for the overall scientific direction of this project. Mr. McIsaac designed the alpha CAMs, developed innovative spectral analysis algorithms for the CAMs, and has authored a number of papers and reports that address alpha CAM performance. He has over 17 years of experience in applied research at the INEL, which makes him highly qualified to direct all aspects of the project and provide guidance for solutions to technical problems as they occur. Mr. McIsaac will share the responsibility of developing of the ${ }^{90} \mathrm{Sr}$ beta detector with Claude W. Sill and Robert J. Gehrke.

- Claude W. Sill, co-PI, is responsible for developing the large-area, ionization chamber alpha spectrometers. For 26 years, Mr. Sill was Chief of the Analytical Chemistry Branch of the Health Services Laboratory at the INEL and for 4 years served as principal scientific ad risor to the Director of the Radiological and Environmental Sciences Laboratory at the INEL providing technical expertise in analytical and radiochemistry and analytical quality control. For the past 10 years, $\mathrm{Mr}$. Sill has operated a radiochemical laboratory and associated counting rooms used for determining alpha-emitting radionuclides in soils and other refractory materials.

- Robert J. Gehrke, co-PI, is responsible for developing the photon analysis spectrometer. Mr. Gehrke has over 28 years experience at the INEL and is the author of 60 refereed publications and 20 meeting presentations in decay scheme studies, $\mathbf{x}$-ray fluorescence, radiation metrology, gamma-ray spectrometry, fast radiochemistry, and radiation measurement techniques. In 1992, Mr. Gehrke was appointed chairman of the American Nuclear Society ANS-41 standards subcommittee, Environmental Remediation of Radioactively Contaminated Sites.

- E. Wayne Killian, co-PI, is responsible for developing the software used to control the operation of the analytical instruments and display, analyze, and archive collected spectral data. Mr. Killian has over 25 years experience at the INEL and is the primary author of VAXGAP, the gamma-ray spectral analysis code that is currently used by the Radiation Measurements Laboratory (RML) at the INEL.

\subsection{Personnel Support Requirements}

All experimental work will be performed by the PIs, or by personnel from the RM\&D and N\&RP Units of EG\&G Idaho who are trained by the PIs. The PIs will be responsible for training RTML operators and testing their qualifications to prepare samples and operate RTML analytical instruments. Each RTML operator will receive 3 to 4 weeks of training. The training will consist of classroom lectures on sample preparation methods and the theory of operation of the RTML analytical instrumentation as well as supervised hands-on training conducted in the RTML. Experiments will be conducted in the RTML and in laboratories at TRA at the INEL. 


\section{DESCRIPTION OF TEST}

\subsection{Introduction}

Analytical techniques that might be used to screen soil samples for ${ }^{90} \mathrm{Sr}$ will be investigated, and selected methods will be evaluated experimentally. Beta counters that have been identified for evaluation include the large-area beta detector ${ }^{3}$ (LABD) developed recently at Pacific Northwest Laboratories (PNL) and a large-area, scintillation beta detector now under development at the INEL. In addition, the following existing RTML analytical technologies will be further developed and tested experimentally: (a) an extended-range, germanium photon analysis spectrometer equipped with an automatic sample changer, (b) two, large-area, ionization chamber alpha spectrometers, and (c) four alpha CAMs.

The ${ }^{90} \mathrm{Sr}$ beta detector being developed at the INEL will measure the high-energy beta particles emitted from ${ }^{90} \mathrm{Sr}$ 's daughter, ${ }^{90} \mathrm{Y}$. When ${ }^{90} \mathrm{Sr}$ and its daughter ${ }^{90} \mathrm{Y}$ are in secular equilibrium in the sample, a measurement of the concentration of ${ }^{90} \mathrm{Y}$ is sufficient to determine the concentration of ${ }^{90} \mathrm{Sr}$. The beta detector will be equipped with a scintillation detector that is covered with a lucite absorber to eliminate beta particles with energies below about $1 \mathrm{MeV}$. Yttrium-90 will be quantified measuring the count rate of beta particles having energies above ahout $1 \mathrm{MeV}$. In the case of the LABD already developed at PNL, the measurement principle is similar, except that detection of highenergy beta particles relies on measuring the coincident count rate in multiple scintillation detectors that are sandwiched together above the sample. The thin rectangular scintillators act as absorbers and coincident counts in multiple scintillators indicates the passage of a high-energy beta particle.

The photon analysis spectrometer simultaneously measures L-shell $\mathrm{x}$-rays and gamma-rays with a high-resolution coaxial germanium detector equipped with a thin entrance window. Plutonium isotopes that decay by alpha emission decay directly to isotopes of uranium. The photon spectrometer determines the presence of plutonium isotopes by counting the L-shell $x$-rays emitted from the uranium daughters following alpha decay of plutonium. It also simultaneously determines the presence of ${ }^{241} \mathrm{Am}$ and fission and activation product isotopes such as ${ }^{60} \mathrm{Co}$ and ${ }^{137} \mathrm{Cs}$ by counting the gamma-rays emitted during their decay. Soil samples are dried and then sieved to remove any particles larger than $300 \mu \mathrm{m}$. Eleven grams of sieved soil are loaded into an $8-\mathrm{mm}$ high $\times 70-\mathrm{mm}$ diameter plastic sample container and counted with the sample container positioned near the face of the end-cap of the germanium detector. This sample size and geometry were chosen to minimize mass absorption effects. Smears and air filters are taped to the center of the base of the same plastic sample container used to analyze soil samples and are counted directly using the same counting geometry.

The large-area, ionization chamber alpha spectrometers determine the presence of TRU isotopes by measuring the pulse height spectrum of alpha particles emitted from the sample. The concentration of a given TRU isotope is deduced from the count rate in the corresponding alpha peak in the collected alpha spectrum. Soil samples are dried, sieved, and finely ground. One 
hundred milligrams of the ground soil are suspended in an aqueous solution containing $30 \%$ ethanol that is sprayed uniformly onto a preheated, $25.4-\mathrm{cm}$ diameter, stainless steel pan. The pan is reheated to evaporate any residual moisture, and following cooling to room temperature, is positioned in a recess in the bottom of the ionization chamber for counting. Air dusts are collected with a high-volume air sampler on $20 \times 25-\mathrm{cm}(8 \times 10$-in. $)$ membrane filters with $1.0-\mu \mathrm{m}$ pores. In the case of air filters, no sample preparation is required prior to counting in the ionization chamber. A milled cutsut in the sample plate is used to position the air filter reproducibly inside the ionization chamber for counting.

The alpha CAMs measure alpha activity in air by pulse-height analysis of the alpha activity removed from air that is sampled. The measurement of airborne alpha-emitting radionuclides is performed by pulling a continuous sample of ambient air through a two-stage inertial impactor and then through a filter having a pore size small enough to trap aerosolized particles. The impactor removes a large fraction of the naturally occurring radon daughter isotopes from the arrstream before it passes through the sample filter. The alpha-emitting radionuclides are attached to the aerosol particles that are trapped by the filter. Alpha activity on the filter is measured by a solid-state silicon detector positioned about $7 \mathrm{~mm}$ from the influent face of the filter. The silicon detector is equipped with a 4-mm thick grid-type collimator to enhance spectral resolution.

\subsubsection{Evaluate Beta Detectors}

Traditional chemical methods used to determine ${ }^{90} \mathrm{Sr}$ in solid samples are laborious and time consuming. Analytical methods that might be used to screen samples for ${ }^{90} \mathrm{Sr}$ that do not require elaborate sample pretreatment and chemical separation will be investigated, and selected methods will be evaluated experimentally. Analytical instruments that have been identified for evaluation include the $\mathrm{LABD}$, recently developed at PNL, and a large-area scintillation beta counter now being developed at the INEL.

When ${ }^{90} \mathrm{Sr}$ and its daughter ${ }^{90} \mathrm{Y}$ are in secular equilibrium in the sample, a measurement of the concentration of ${ }^{90} \mathrm{Y}$ is sufficient to determine the concentration of ${ }^{90} \mathrm{Sr}$. Soil samples will be dried and then sieved to remove any particles larger than $300 \mu \mathrm{m}$. In the case of the large-area scintillation detector being developed at the INEL, 50 to $100 \mathrm{~g}$ of sieved soil will be spread uniformly over a $30.5-\mathrm{cm}$ diameter steel pan having a surface area of $730 \mathrm{~cm}^{2}$. A thin absorber of low $\mathrm{Z}$ material will be positioned between the sample and scintillation detector to eliminate beta particles with energies below about $1 \mathrm{MeV}$. (The optimum sample and absorber thicknesses will be determined empirically). The thickness of the scintillation detector will be made small to make it transparent to bremsstrahlung radiation and gamma-rays that pass through the absorber. Smears and air filters will be taped to the center of the same plate used to aralyze soil samples and will be counted directly using the same counting geometry. Yttrium-90 will be quantified measuring the count rate of beta particles having energies above the cutoff energy. 
In the case of the LABD already developed at PNL, the measurement principle is similar, except that detection of high-energy beta particles relies on measuring the coincident count rate in multiple scintillation detectors that are sandwiched together. The thin rectangular scintillators act as absorbers and coincident counts in multiple scintillators indicates the passage of a high-energy beta particle.

The sensitivities of the scintillation beta detectors for detection of ${ }^{90} \mathrm{Sr}$ will be dependent in part on the intensity of the high-energy beta radiation that is emitted from the sample from isotopes other than ${ }^{90} \mathrm{Y}$. Beta decay data for ${ }^{90} \mathrm{Sr}$, ${ }^{90} \mathrm{Y}$, and other long-lived fission and activation product radionuclides are listed in Table 1. Similar data for members of th: three natural radioactive decay chains and the manmade neptunium decay chain that decay by emitting high-energy beta particles are also listed in Table 1. As shown in Table 1, the endpoint energy of the ${ }^{90} \mathrm{Sr}$ beta particle is $546 \mathrm{keV}$ while that for ${ }^{90} \mathrm{Y}$ is $2.28 \mathrm{MeV}$. Greater than $69 \%$ of the beta particles emitted during the decay of ${ }^{90} \mathrm{Y}$ have energies above the endpoint energy of the beta particles emitted by ${ }^{90} \mathrm{Sr}$, and about $27 \%$ of the beta particles emitted during the decay of ${ }^{90} \mathrm{Y}$ have energies above $1.3 \mathrm{MeV}$. The intensities of the beta particles having energies above $1.3 \mathrm{MeV}$ emitted from the long-lived fission and activation products are all less than $1 \%$. Only ${ }^{228} \mathrm{Ac},{ }^{212} \mathrm{Bi},{ }^{208} \mathrm{Tl},{ }^{234 \mathrm{~m}} \mathrm{~Pa}$, and ${ }^{214} \mathrm{Si}$ emit beta particles with energies above $1.3 \mathrm{MeV}$ with any appreciable intensity. The average concentration of each of these five radionuclides in soil is expected to be about $1 \mathrm{pCi} / \mathrm{g}$. Based on the intensities given in Table 1 , an ${ }^{90} \mathrm{Y}$ concentration of about $3 \mathrm{pCi} / \mathrm{g}$ will yield a count rate twice the background beta particle count rate if an absorber $:$ chosen that eliminates beta particles with energies below $1.3 \mathrm{MeV}$.

\subsubsection{Upgrade Photon Analysis Spectrometer Software}

For each sample analyzed with the thin-window germanium spectrometer, a spectrum is obtained that identifies both the $x$-rays and gamma-rays emitted from the sample over the energy range 10 to $1,380 \mathrm{keV}$. The $\mathrm{x}$-ray region of the spectrum is analyzed using the code LXRAY, and the gamma-ray portion of the spectrum is analyzed concurrently using the code VAXGAP. The statistical calculations now performed by the LXRAY spectrum analysis code are incomplete and underestimate the uncertainty in the reported plutonium and ${ }^{241} \mathrm{Am}$ concentrations in soil samples. The $\mathrm{x}$-ray analysis software will be upgraded so that uncertainties are calculated to include contributions from the finite size of the zero and gain shifts. Using an approach similar to that used to account for variations in the gain and $z c^{\circ}$

LXRAY program will be upgraded to permit the background scaling factor to vary so as $t$. arch for the best background value. The current LXRAY program allows parameters such as gain and zero to vary only by fixed increments and in a fixed order. For samples containing no ${ }^{241} \mathrm{Am}$, gain and zero shifts would be handled better by a methodology, which could make use of this information. In this case, the order of steps and magnitude of the increments would depend upon the spectral data.

Corrections for cascade coincidence summing will be calculaied and incorporated into the software used to analyze photon analysis spectrometer gamma-ray spectra. 
Table 1. Summary of beta decay data for ${ }^{90} \mathrm{Sr},{ }^{90} \mathrm{Y}$, long-lived fission and activation products, and naturally occurring isotopes.

\begin{tabular}{lcccccc}
\hline & $\begin{array}{c}\text { Probability of } \\
\text { emission } \\
(\%)\end{array}$ & $\begin{array}{c}\text { Average } \\
\text { energy } \\
(\mathrm{keV})\end{array}$ & $\begin{array}{c}\text { Endpoint } \\
\text { energy } \\
(\mathrm{keV})\end{array}$ & $\begin{array}{c}\text { Intensity } \\
\text { above } \\
600 \mathrm{keV} \\
(\%)\end{array}$ & $\begin{array}{c}\text { Intensity } \\
\text { above } \\
1,300 \mathrm{keV} \\
(\%)\end{array}$ \\
\hline Nuclide & Half-life & 100 & 196 & 546 & 0.0 & 0.0 \\
${ }^{90} \mathrm{Sr}$ & $28.5 \mathrm{y}$ & 100 & 934 & 2,282 & 69.4 & 26.9 \\
${ }^{90} \mathrm{Y}$ & $2.67 \mathrm{~d}$ & & & &
\end{tabular}

Fission and activation products:

\begin{tabular}{llcrlll}
${ }^{36} \mathrm{Cl}$ & $3.01 \times 10^{5} \mathrm{y}$ & 98.1 & 246 & 1,142 & 1.10 & 0.0 \\
${ }^{60} \mathrm{Co}$ & $5.271 \mathrm{y}$ & 100 & 96 & 1,491 & 0.04 & 0.0 \\
${ }^{137} \mathrm{Cs}^{\mathrm{a}}$ & $30.0 \mathrm{y}$ & 100 & 188 & 1,175 & 1.40 & 0.0 \\
${ }^{152} \mathrm{Eu}$ & $13.3 \mathrm{y}$ & 27.9 & 83 & 1,754 & 3.64 & 0.05 \\
${ }^{154} \mathrm{Eu}$ & $8.8 \mathrm{y}$ & 100 & 227 & 1,846 & 7.83 & 0.93 \\
\hline${ }^{40} \mathrm{~K}$ & $1.28 \times 10^{9} \mathrm{y}$ & 89.3 & 455 & 1,505 & 33.4 & 0.0 \\
\hline
\end{tabular}

Thorium series $\left({ }^{232} \mathrm{Th}->>{ }^{228} \mathrm{Ra}->>{ }^{228} \mathrm{Ac}->\right.$ etc.):

\begin{tabular}{lcccccc}
${ }^{228} \mathrm{Ac}$ & $6.13 \mathrm{~h}$ & 100 & 391 & 2,079 & 22.6 & 1.99 \\
${ }^{212} \mathrm{Bi}$ & $1.01 \mathrm{~h}$ & 64.1 & 492 & 2,246 & 37.3 & 10.4 \\
${ }^{208} \mathrm{~T} 7$ & $3.05 \mathrm{~m}$ & 100 & 560 & 2,377 & 42.0 & 3.2 \\
\hline
\end{tabular}

Neptunium series $\left({ }^{241} \mathrm{Pu}-.>{ }^{241} \mathrm{Am}->{ }^{237} \mathrm{~Np} \mathrm{-->} \mathrm{etc.):}\right.$

\begin{tabular}{|c|c|c|c|c|c|c|}
\hline $\begin{array}{l}{ }^{213} \mathrm{Bi} \\
{ }^{209} \mathrm{Ti}^{\mathrm{b}}\end{array}$ & $\begin{array}{l}45.6 \mathrm{~m} \\
2.2 \mathrm{~m}\end{array}$ & $\begin{array}{c}97.8 \\
100\end{array}$ & $\begin{array}{l}444 \\
659\end{array}$ & $\begin{array}{l}1,420 \\
1,824\end{array}$ & $\begin{array}{l}29.6 \\
52.4\end{array}$ & 0.1 \\
\hline
\end{tabular}

Uranium series $\left({ }^{238} \mathrm{U}\right.$-.> ${ }^{234} \mathrm{Th}$-.> ${ }^{234} \mathrm{~Pa}^{\mathrm{m}}$..> etc. $)$ :

\begin{tabular}{|c|c|c|c|c|c|c|}
\hline${ }^{234} \mathrm{~m} \mathrm{~Pa}$ & $1.17 \mathrm{~m}$ & 99.9 & 819 & 2,281 & 62.7 & 18.4 \\
\hline${ }^{214} \mathrm{~Pb}$ & $26.8 \mathrm{~m}$ & 100 & 220 & 1,024 & 1.5 & 0.0 \\
\hline${ }^{214} \mathrm{Bi}$ & $19.9 \mathrm{~m}$ & 100 & 641 & 3,270 & 43.5 & 9.8 \\
\hline${ }^{210} \mathrm{Bi}$ & $5.01 \mathrm{~d}$ & 100 & 389 & 1,161 & 21.7 & 0.0 \\
\hline
\end{tabular}

Actinium series $\left({ }^{235} \mathrm{U}\right.$-.> ${ }^{231} \mathrm{Th}$-.> ${ }^{231} \mathrm{~Pa}$--> etc. $)$ :

\begin{tabular}{lllllll}
${ }^{211} \mathrm{~Pb}$ & $36.1 \mathrm{~m}$ & 100 & 447 & 1,373 & 30.2 & 0.04 \\
${ }^{207} \mathrm{~T}$ & $4.8 \mathrm{~m}$ & 100 & 493 & 1,422 & 35.6 & 0.19 \\
\hline
\end{tabular}

a. ${ }^{137 \mathrm{~m}} \mathrm{Ba}$ emits conversion electrons with energies of 624 and $656 \mathrm{keV}$ having intensities of 8.33 and $1.52 \%$, respectively.

b. The parent of ${ }^{209} \mathrm{Tl},{ }^{213} \mathrm{Bi}$ decays to ${ }^{209} \mathrm{Tl}$ only $2.2 \%$ of the time. 
An off-line spectrum analysis capability will be developed to permit the reanalysis of spectral data that failed certain performance checks. This software will have the flexibility to reanalyze spectral data using different components or backgrounds and will allow for zero and gain shifts beyond the capability of the analysis software used for routine analysis.

Modifications to the LXRAY spectrum analysis program will be tested experimentally. Calibration standards and blanks representing each sample type will be analyzed to validate and assess the benefit of the modifications made to the spectrum analysis code.

\subsubsection{Upgrade Alpha Spectral Analysis Software}

Previous work has shown that, in the case of spectra collected using the alpha CAMs, the background under the ${ }^{239} \mathrm{Pu}$ and ${ }^{241} \mathrm{Am}$ alpha peaks is strongly affected by the concentration of dust in the air being sampled. Similarly, in the case of alpha spectra collected using the ionization chambers, the background and counting efficiency in the region of the TRU alpha peaks are affected by irregularities in the distribution of the sample over the sample pan or membrane filter. Alpha spectrum analysis techniques that have been developed and adopted by the RTML will be refined and tested experimentally to determine the adequacy of the background correction methods over a range of experimental conditions. The alpha CAMs will be tested in environments with relatively high airborne dust concentrations to determine the practical operating limits of the fixed-filter design. Methods of spraying soil suspensions on steel sample pans will be improved to decrease losses and increase spectral resolution. Additional experimental work will be done to determine which filters should be used to collect smear and air filter samples for analysis with the large-area, ionization chamber alpha spectrometers. Because certain filters that provide excellent spectral resolution are also quite expensive, a number of candidate filters should be tested and the data subjected to a cost benefit analysis. Based on the results of these evaluations, existing RTML alpha spectrum analysis software will be modified to improve analysis reliability and sensitivity.

\subsection{Location, Duration, and Schedule of Tests}

All software upgrades and experimental testing will be performed at TRA on an ongoing basis during FY-94. Full-scale operation estimates are given in Appendix A, and assessments of Comprehensive Environmental Response, Compensation, and Liability Act (CERCLA) criteria are given in Appendix B. The cost estimate elements and CERCLA criteria itemized in Tables A-1 and B-1 were taken from Tables 1 and 2 of the Buried Waste Integrated Demonstration Technology Test Plan Guidance. ${ }^{4}$ 


\section{TASKS AND SEQUENCE OF ACTIVITIES}

A summary of the dates the FY-94 tasks to be started and completed are summarized in Table 2.

Table 2. Activity/milestone summary for FY-94.

\begin{tabular}{lcc}
\hline Activity/milestone & Start date & $\begin{array}{c}\text { Completion } \\
\text { date }\end{array}$ \\
\hline Modify and test LXRAY and VAXGAP codes & $10 / 01 / 93$ & $07 / 01 / 94$ \\
Develop alpha spectral analysis codes & $11 / 30 / 93$ & $03 / 20 / 94$ \\
Test beta detectors & $01 / 01 / 94$ & $07 / 01 / 94$ \\
Write three journal articles & $01 / 03 / 94$ & $08 / 30 / 94$ \\
Write draft final report & $06 / 28 / 94$ & $08 / 30 / 94$ \\
\hline
\end{tabular}




\section{SAMPLING AND DATA COLLECTION}

No environmental samples will be collected for analysis. Experimental evaluations will be performed using soil, smear, and air filter standards prepared using standard soils and radioactive reference materials traceable to the National Institute of Standards and Technology (NIST). In the case of the photon spectrometer, ionization chambers, and alpha CAMs, data collected consist of alpha and photon spectra from well-known blanks and prepared standards. Data collected during the evaluation of the beta detectors consist of count rates from well-known blanks and prepared standards.

\subsection{Data Collection Techniques}

Procedures governing the handling of radioactive materials, liquid nitrogen, and performance of laboratory activities are provided in the EG\&G Idaho Company Procedures Manual and in the procedures manual for the RTML. These procedures will be adhered to during all experimental work.

\subsubsection{Beta Detectors}

No standard operating procedures have been developed yet for the beta detectors. In the case of the LABD, knowledgeable personnel from PNL will deliver the system to the INEL and teach the PIs how to operate it.

The beta detectors will be evaluated measuring well-known blank soils and standard soils containing known activities of ${ }^{90} \mathrm{~S} r$ in equilibrium with ${ }^{90} \mathrm{Y}$. In addition, measurements will be made of standard soils containing ${ }^{90} \mathrm{Sr} /{ }^{90} \mathrm{Y}$ and a gamma-ray emitting isotope such as ${ }^{60} \mathrm{Co}$ or ${ }^{137} \mathrm{Cs}$ to determine how to correct or eliminate counts due to gamma-rays emitted from the sample. In the case of the large-area scintillation detector being developed at the INEL, 50 to $100 \mathrm{~g}$ of each soil standard will be spread uniformly over a $30.5-\mathrm{cm}$ diameter steel pan having a surface area of $730 \mathrm{~cm}^{2}$. Each standard will first be counted without a beta absorber between the sample and scintillator. The sample will then be recounted with various thicknesses of lucite inserted between the sample and scintillator to determine an optimum beta absorber thickness for measuring the high-energy beta particles emitted by ${ }^{90} \mathrm{Y}$. Smear standards will be fixed to the center of the same plate used to analyze soil samples and will be counted using the same counting geometry. Following each analysis, the sample description and identification number, count time, and total counts will be recorded in a laboratory notebook for permanent reference. A calibration curve will be generated that relates measured count rate to the ${ }^{90} \mathrm{Sr} /{ }^{90} \mathrm{Y}$ concentration in the sample.

In the case of the LABD already developed at PNL, the measurement principle is similar, except that detection of high-energy beta particles relies on measuring the coincident count rate in multiple scintillation detectors that are sandwiched together above the sample. The thin rectargular scintillators act as absorbers and coincident counts in multiple scintillators indicates the passage of 
a high-energy beta particle. The same standard soils and smears prepared for the INEL's large-area, scintillation beta detector will be used to experimentally evaluate the LABD. Following each analysis, the sample description and identification number, count time, and total counts will be recorded in a laboratory notebook for permanent reference. A calibration curve will be generated that relates measured coincidence count rate to the ${ }^{90} \mathrm{Sr} /{ }^{90} \mathrm{Y}$ concentration in the sample.

\subsubsection{Large-area Ionization Chamber Alpha Spectrometers}

The principles of operation and operating procedures for the large-area, ionization chamber alpha spectrometers are described in the operating procedures for the RTML. ${ }^{1}$ Standard soils containing known activities of ${ }^{234} \mathrm{U},{ }^{238} \mathrm{U},{ }^{238} \mathrm{Pu},{ }^{239} \mathrm{Pu}$, and/or ${ }^{241} \mathrm{Am}$ and samples of pitchblende, uranium ore, mill tailings, and fertilizer shale will be analyzed to obtain alpha spectra needed to further develop spectral analysis algorithms. These spectra will be automatically stored in computer memory following the completion of each count. Sample identification number, description, count time, and spectrum identification number will be recorded in a laboratory notebook for permanent reference.

\subsubsection{Photon Analysis Spectrometer}

The principles of operation and operating procedures for the photon analysis spectrometer are described in the operating procedures for the RTML. ${ }^{1}$ Standard soils containing known activities of ${ }^{238} \mathrm{Pu},{ }^{239} \mathrm{Pu},{ }^{241} \mathrm{Am},{ }^{60} \mathrm{Co}$, and/or ${ }^{137} \mathrm{Cs}$ will be analyzed to obtain $\mathrm{x}$-ray/gamma-ray spectra needed to further develop the LXRAY and VAXGAP photon spectral analysis programs. Before counting is initiated, a count que is constructed using the XGAP program. For each of the samples to be counted, a sample identification number, sample description, and count time are entered into a counting que. Automatic analysis of a set of samples is started by entering the command "GOQ" on the photon spectrometer's X-terminal. Following the completion of counting of each sample, the photon spectrum is stored in computer memory, and the LXRAY and VAXGAP programs automatically analyze the $x$-ray and gamma-ray regions of the spectrum and print the results on the laser printer.

\subsubsection{Alpha Continuous Air Monitors}

The principles of operation and operating procedures for the alpha CAMs are described in the operating procedures for the RTML. ${ }^{1}$ Prior to operation, a Millipore, $47-\mathrm{mm}$ diameter Fluoropore filter with a pore size of $1.0 \mu \mathrm{m}$ must be installed in the CAM filter holder. Access to the filter holder is achieved through the rear door of the air sampling cabinet. A switch mounted to an internal shelf automatically shuts off the detector bias voltage when the rear cabinet door is opened. The filter holder, which is located at the bottom of the virtual impactor, is removed from the impactor body by turning it one-half turn counter-clockwise. Using tweezers, the $47-\mathrm{mm}$ diameter filter is placed over the fine-mesh screen in the filter holder and centered. Once the filter is centered, the air sampling pumps are turned on to hold the filter in place during the installation of the filter holder. The air sampling pumps are turned on with the power switch located in the upper 
right-hand corner of the rear frame of the cabinet. The filter holder is secured to the impactor body by inserting it into the filter holder receptacle at the bottom of the impactor body and turning it clockwise one-halí turn.

Using the alpha CAM X-terminal located in the RTML anatwsis trailer, spectrum accumulation is initiated using the ACAM program by entering the command "START;", the desired counting time in seconds, and depressing the "RETURN" key. When spectrum accumulation is started, the spcctrum for the CAM will be displayed in the spectrum display window on the CAM X-terminal monitor corresponding to the CAM. The impactor exhaust and filter effluent air flow rates for each CAM will be displayed below the corresponding alpha spectrum.

Following the completion of a sampling cycle, the filter is removed from the filter holder using the following procedure. The filter holder is removed from the impactor body by turning it one-half turn counterclockwise. This operation is performed with the air sampling pumps running so that the filter remains with the filter holder during removal. When the filter holder is disengaged, the air sampling pumps are turned off. The filter is transferred from the filter holder to a 2 -in. diameter petri dish, and a new filter is installed using the procedure previously described. 


\section{DOCUMENT CONTROL}

\subsection{Data}

Copies of all raw and validated data will be stored on the RTML VAX 4000. All software programs and spectral data are copied bimonthly to a backup tape. The BWID Program Directive $3.3^{\mathrm{a}}$ requires that all copies of data and $\log$ books shall be provided to BWID on a daily basis during BWID-approved testing and/or demonstrations. The FY-94 RTML work is exempt from this requirement since the RTML will not be field tested during FY-94 in a BWID-approved demonstration.

\subsection{Test Plan}

This test plan will be revised as required and controlled by the PIs. Only the PIs can authorize deviations from this test plan. Deviations from this test plan will be documenied in laboratory notebooks.

\subsection{Other Documents}

Laboratory notebooks will be maintained by the RM\&D and N\&PR Units for the large-area, ionization chamber alpha spectrometer, photon analysis spectrometer, alpha CAMs, and VAX 4000 model 100 computer. Instrument calibration results for each measurement system will be documented in the project file or instrument logbook. Any changes made to settings or maintenance performed will be noted in the laboratory notebook assigned to the system.

a. Buried Waste Integrated Demonstration Program Manual, EG\&G Idaho, Inc., February 1994. 


\section{ANALYTICAL METHODS}

Detailed operating procedures for the RTML are presented in Operating Procedures for Rapid Transuranic Monitoring Laboratory. ${ }^{1}$ These procedures describe the methods used to prepare and analyze soil, smear, and air filter samples. 


\section{DATA REDUCTION, VALIDATION, AND VERIFICATION}

\subsection{Data Quality Objectives}

Data quality objectives of the FY-94 work focus primarily on determining the sensitivity of each measurement system for detection of TRU and/or fission product radionuclides using counting times of 30 minutes or less. Technical performance goals include producing field-deployable measurement systems with the following sensitivities: (a) an alpha CAM system with a sensitivity for airborne TRU isotopes that is superior to the sensitivity of $8 \mathrm{DAC}-\mathrm{h}$ required by DOE Order 5480.11 , (b) a large-area, ionization chamber alpha spectrometer capable of analyzing soil samples in $\mathbf{3 0}$ minutes or less with a LLD concentration of $50 \mathrm{pCi} / \mathrm{g}$ for TRU isotopes and air samples with a $\mathrm{LLD}$ of 0.1 DAC-h, and (c) a photon analysis spectrometer capable of analyzing soil samples in 30 minutes or less with LLDs of $50 \mathrm{pCi} / \mathrm{g}$ for plutonium, $1 \mathrm{pCi} / \mathrm{g}$ for ${ }^{241} \mathrm{Am}, 4 \mathrm{pCi} / \mathrm{g}$ for ${ }^{60} \mathrm{Co}$, and $3 \mathrm{pCi} / \mathrm{g}$ for ${ }^{137} \mathrm{Cs}$. The technical performance goals also include identifying, and possibly developing, a field-deployable beta counter capable of screening soil samples for ${ }^{90} \mathrm{Sr}$ at concentrations below $100 \mathrm{pCi} / \mathrm{g}$.

\subsection{Data Reduction Scheme}

Alpha and x-ray/gamma-ray spectra will be analyzed using software programs installed on the VAX 4000 model 100 computer. Photon spectra collected using the photon analysis spectrometer will be analyzed automatically using the program XGAP, which is a combination of the LXRAY and VAXGAP programs that analyze, respectively, the $x$-ray and gamma-ray regions of each spectrum. Alpha spectra collected using the four alpha CAMs and two ionization chambers will be analyzed automatically using the ACAM and ION programs, respectively. Both programs now analyze alpha spectra by means of region-of-interest (ROI) analysis algorithms.

The methodology of Currie ${ }^{5}$ is being used to calculate the LLD activity concentrations of the analytical measurements. His equation for paired observations of sample and background with a probability of 0.05 that activity will be detected when none is present or that activity will not be detected when, in fact, it is present is

$$
L L D=2.71+4.66 B^{1 / 2}
$$

In terms of concentration in soil, expressed as $\mathrm{pCi} / \mathrm{g}$, the equation becomes

$$
L L D=\frac{2.71+4.66 B^{1 / 2}}{2.22 \cdot T \cdot \epsilon \cdot Y \cdot M}
$$

where

B = total number of background counts in the ROI (counts)

$2.22=$ number of disintegrations per minute per $\mathrm{pCi}$ 
$\mathrm{T}=$ counting time (minutes)

$\epsilon \quad=$ absolute counting efficiency (counts per disintegration)

$\mathrm{Y}=$ fractional recovery in the $\mathrm{ROI}$

$\mathbf{M}=$ mass of sample $(\mathrm{g})$.

In the case of the large-area ionization chamber and germanium spectrometers. activities in each sample are calculated automatically using the spectrum analysis programs ION and XGAP, respectively. In the case of the alpha CAMs, airborne TRU concentrations are automatically calculated and plotted using the ACAM program. The three spectrum analysis programs are installed on the VAX computer in the RTML analysis trailer.

For the large-area, ionization chamber alpha spectrometers, the net area of each TRU alpha peak is determined by subtracting from the gross counts in the peak the counts contributed by instrument background and the low-energy tails of the ${ }^{218} \mathrm{Po} /{ }^{212} \mathrm{Bi}$ and ${ }^{214} \mathrm{Po}$ peaks. In the case of soil samples, activity concentration, $\mathrm{C}_{\mathrm{l}}$, expressed as $\mathrm{pCi} / \mathrm{g}$ is calculated as

$$
C_{l}=\frac{C_{G}-B_{i}-\left(k_{1} \cdot R_{1}\right)-\left(k_{2} \cdot R_{2}\right)}{2.22 \cdot \epsilon \cdot T \cdot M}
$$

where

$\mathrm{C}_{\mathrm{G}}=$ total counts in TRU alpha peak (counts)

$B_{i} \quad=$ instrument background in TRU alpha peak (countis)

$k_{1}=$ fraction of counts in background ROI, $R_{1}$, that fall in energy region of TRU alpha peak

$R_{1}=\mathrm{ROI}$ encompassing ${ }^{218} \mathrm{Po} /{ }^{212} \mathrm{Bi}$ peak

$k_{2}=$ fraction of counts in background ROI, $R_{2}$ that fall in energy region of TRU alpha peak

$R_{2}=\mathrm{ROI}$ encompassing ${ }^{214}$ Po peak

$2.22=$ number of disintegrations per minute per $\mathrm{pCi}$

$\epsilon \quad=$ absolute counting efficiency (counts per disintegration)

$\mathrm{T}=$ count time (minutes)

$\mathrm{M}$ = sample mass $(\mathrm{g})$. 
In the case of the photon analysis spectrometer, the net number of counts in each $\mathrm{L} x$-ray peak is determined using the LXRAY subroutine of the XGAP program, and the net number of counts in each gamma-ray peak is determined using the VAXGAP subroutine of the XGAP program. For a soil sample, activity concentration, $\mathrm{C}_{\mathrm{X}}$, expressed as $\mathrm{pCi} / \mathrm{g}$, is calculated as

$$
C_{\chi}=\frac{C_{N}}{2.22 \cdot P \cdot \epsilon \cdot T \cdot M}
$$

where

$\mathrm{C}_{\mathrm{N}}=$ net counts in $\mathrm{x}$-ray or gamma-ray peak

$\mathbf{P} \quad=$ emission probability of $\mathbf{x}$-ray or gamma-ray and

other terms are as previously defined.

In the case of the alpha CAMs, the airborne concentration of a TRU isotope during the first sampling interval, $\mathrm{X}_{1}$ expressed as $\mathrm{pCi} / \mathrm{L}$, is calculated as

$$
X_{1}=\frac{C_{1}}{2.22 \cdot \epsilon \cdot Y \cdot F_{1} \cdot \frac{T_{1}^{2}}{2}}
$$

where

$\mathrm{C}_{1}=$ net counts in TRU alpha peak during first sampling interval (counts)

$\mathrm{Y}=$ activity collection efficiency of CAM

$\mathrm{F}_{1}=$ average flow rate during first sampling interval $(\mathrm{L} / \mathrm{min})$

$\mathrm{T}_{1}=$ length of first sampling interval $(\mathrm{min})$ and

other terms are as previously dcfined.

The airborne TRU concentration during the second sampling interval is calculated as

$$
X_{2}=\frac{C_{2}-C_{1}-2 C_{1}\left(T_{2} / T_{1}\right)}{2.22 \cdot \epsilon \cdot Y \cdot F_{2} \cdot \frac{T_{2}^{2}}{2}}
$$


where

$C_{2}=$ net counts in TRU alpha peak at end of second sampling interval (counts)

$F_{2}=$ average flow rate during second sampling interval $(\mathrm{L} / \mathrm{min})$

$T_{2}=$ length of second sampling interval ( $\left.\min \right)$.

The airborne TRU concentration during each subsequent sampling interval, $X_{n}$, expressed as $\mathrm{pCi} / \mathrm{L}$, is calculated as

$$
X_{n}=\frac{\left(C_{n}-C_{n-1}\right)-\left(C_{n-1}-C_{n-2}\right)\left(T_{n} / T_{n-1}\right)}{2.22 \cdot \epsilon \cdot Y \cdot F_{n} \frac{\cdot T_{n}^{2}}{2}}-X_{n-1} \cdot\left(T_{n-1} / T_{n}\right)\left(F_{n-1} / F_{n}\right)
$$

where

$C_{n}=$ net counts in TRU alpha peak at end of sampling interval $n$ (counts)

$F_{n}=$ average flow rate during sampling interval $n(L / m i n)$ and

$T_{n}=$ length of sampling interval $n(\min )$.

The total counts in the ${ }^{239} \mathrm{Pu} /{ }^{241} \mathrm{Am} \mathrm{ROI}$ are determined by simply summing the counts in the alpha CAM spectrum from 3.71 to $5.60 \mathrm{MeV}$, an energy range that encompasses the energies of the alpha particles emitted by ${ }^{239} \mathrm{Pu}$ and ${ }^{241} \mathrm{Am}$. The number of background counts in the same region is determined using a linear regression method. The counts in 16 channels on the low-energy side of the ${ }^{218} \mathrm{Po} /{ }^{212} \mathrm{Bi}$ alpha peak at $6.00 \mathrm{MeV}$ are fit to the following exponential function:

$$
S_{i}=Y \exp \left[\left(X_{i}-C\right) k n\right]
$$

where

$$
\begin{aligned}
& S_{i}=\text { background counts in channel } i \\
& Y=\text { counts in channel } C \\
& X_{i}=\text { channel } i \text { (from } C-10 \text { to } C+5 \text { ) } \\
& C=\text { channel } 14 \text { channels below the centroid of the } 6.00 \mathrm{MeV} \text { peak }
\end{aligned}
$$


$k_{n}=$ coefficient whose value is determined by fitting the background count data to the channel data.

The number of background counts in each channel from 3.71 to $5.60 \mathrm{MeV}, \mathrm{B}_{\mathrm{i}}$, is then calculated as

$$
\begin{aligned}
& B_{i}=S_{1} \text { when } S_{1}>Z \\
& B_{1}=Z \text { when } S_{1} \leq Z
\end{aligned}
$$

where

$\mathrm{Z}=$ the average number of counts in the 10 channels from 3.57 to $3.71 \mathrm{MeV}$.

The total number of background counts from 3.71 to $5.60 \mathrm{MeV}$ is then calculated by summing the counts per channel estimated using Equation 8 over channels from 3.71 to $5.60 \mathrm{MeV}$. The net counts in the ${ }^{239} \mathrm{Pu} /{ }^{241} \mathrm{Am} \mathrm{ROI}$ are then estimated by subtracting the calculated background counts from the total counts between 3.71 and $5.60 \mathrm{MeV}$.

The four RTML alpha CAMs will be installed in a laboratory at TRA and tested by sampling ambient air and laboratory-generated atmospheres laden with either blank dust or dust spiked with $\mathrm{nCi} / \mathrm{g}$ concentrations of ${ }^{239} \mathrm{Pu}$ and/or ${ }^{241} \mathrm{Am}$. During air sampling, the cumulative alpha spectrum will be transferred to the VAX computer and analyzed at regular intervals. The operator will select the length of the interval prior to the start of sampling, using an interval of 15,30 , or 60 minutes. Following each analysis of the cumulative alpha spectrum, the date, real time since the start of sampling, average sampling flow rate during the interval, total number of counts in the ${ }^{239} \mathrm{Pu} /{ }^{241} \mathrm{Am}$ $\mathrm{ROI}$, net number of counts in the ${ }^{239} \mathrm{Pu} /{ }^{241} \mathrm{Am} \mathrm{ROI}$, the average airborne ${ }^{239} \mathrm{Pu} /{ }^{241} \mathrm{Am}$ concentration during the interval, expressed as $\mathrm{pCi} / \mathrm{L}$, and its estimated uncertainty, expressed in percent, will be automatically stored in computer memory. A hard copy of the analysis results will be printed on the laser printer.

\subsection{Data Reporting}

Data collected during testing will be evaluated and documented in an EG\&G Idaho informal report. Data included in the report will be qualified by the PIs and will be subjected to peer review. Data that will be presented in the report include

- LLD activities or concentrations of ${ }^{239} \mathrm{Pu}$ and ${ }^{241} \mathrm{Am}$ in soils, smears, and airborne dust determined for the large-area, ionization chamber alpha spectrometers

- LLD activities or concentrations of $\mathrm{Pu},{ }^{241} \mathrm{Am},{ }^{60} \mathrm{Co}$, and ${ }^{137} \mathrm{Cs}$ in soils, smears, and airborne dust determined for the photon analysis spectrometer

- LLD concentration of airborne ${ }^{239} \mathrm{Pu}$ determined for each of the four alpha CAMs 
- LLD activities or concentrations of ${ }^{90} \mathrm{Sr}$ in soils, smears, and airborne dust determined for the PNL's LABD and INEL's large-area, scintillation beta counter

- Sample throughput rates for the large-area, ionization chamber spectrometers and photon analysis spectrometer.

In addition, the report will present qualitative assessments of

- RTML hardware and software performance

- Procedures used to collect, prepare, and analyze soil, smear, and airborne dust samples. 


\section{QUALITY ASSURANCE}

\subsection{Quality Level}

The quality level for the RTML mobile laboratory hardware and software upgrades will be level "B." All activities will follow the guidance in the EG\&G Idaho Quality Manual. The Quality Program Plan used is QPP-060. The policies described in QP-15, "Control of Nonconforming Items," are invoked with the clarifications described in Sections 3.15.1, 3.15.2, and 3.15.3 of QPP-060.

\subsection{Quality Control Methods}

\subsubsection{Replicate Blanks}

Standard soils containing no added manmade radioactivity will be analyzed to determine spectral backgrounds.

\subsubsection{Standards}

Standard soils containing known quantities of ${ }^{239} \mathrm{Pu},{ }^{241} \mathrm{Am},{ }^{60} \mathrm{Co}$, and/or ${ }^{137} \mathrm{Cs}$ were prepared during FY-93, some at levels only slightly higher than the expected LLD concentrations to validate their values, and some others several times higher to evaluate the accuracy obtainable when better statistical precision can be achieved. Additional standards similar to those prepared during FY-93 will be prepared during FY-94 with concentrations well below the LLDs that can now be achieved using 10 to 15 -minute counting times to determine unequivocally the LLDs that can be achieved using longer counting times. In addition, standard soils containing ${ }^{90} \mathrm{Sr} /{ }^{90} \mathrm{Y},{ }^{60} \mathrm{Co}$, and ${ }^{137} \mathrm{Cs}$ will be prepared for use in evaluating the PNL and INEL beta detectors. The standards will be prepared by Claude W. Sill using radioactive reference materials traceable to NIST. The standards will be controlled and maintained by the PIs.

\subsubsection{Cross Contamination}

Cross contamination among samples is always a problem when large numbers of samples must be dried, sieved, and ground close to one another using nondisposable equipment. This is particularly tiue in a mobile laboratory without running water and sewage facilities. For this reason, a gravityflow oven is used, without forced air circulation, to dry the soil samples. Soil samples are dried in inexpensive aluminum pans that are discarded when the dried soil is transferred to the sieve. Nondisposable items such the mortar, pestle, and hand sprayer are cleaned between each use with $4 \underline{M}$ nitric acid. The nondisposable, stainless steel sample pans currently used to prepare samples for analysis with the large-area ionization chambers are cleaned following analysis. Each pan is first scrubbed in a water bath using a soft sponge to remove the soil adhered to the surface of the pan and is then dipped in a second water bath to remove any residual soil. The pan is next immersed in 
$4 \mathrm{M}$ nitric acid for 24 hours to remove any residual radioactivity. Following immersion in the nitric acid bath, the pan is dipped in a third water bath and allowed to dry at room temperature.

\subsubsection{Self-Assessment Program}

Self assessments are performed according to the Nuclear Research and Engineering Group selfassessment schedule following Company Procedure 1.7. This will meet the requirements of BWID Program Directive 3.2.

\subsection{Routine Procedures to Achieve Precision and Accuracy}

The precision of measurements made using the large-area, ionization chamber a tha spectrometers, photon spectrometer, and alpha CAMs is dictated primarily by Poisson statistics and the uncertainiy of background estimates. Therefore, instrument precision is dependent on factors such as quantity of activity present in the sample and the counting time used to analyze the sample. Instrument precision will be determined by analyzing given standards multiple times.

The accuracy of measurements made using the RTML measurement systems is dependent on counting statistics, uncertainty of estimated backgrounds, quantity of activity present in the sample, counting time, and uncertainties of parameters used to calculate isotopes concentration such as sample preparation yield, sample mass or volume, and absolute counting efficiency. Instrument accuracy will be determined by analyzing standards prepared with radioactive reference material traceable to NIST with sample geometries that are the same as the unknown samples. 


\section{EQUIPMENT}

This section describes the main structural components of the RTML, equipment used to prepare samples for analysis, laboratory instruments used to analyze samples, and type of data that will be collected.

\subsection{RTML Configuration}

A block diagram of the RTML electronics is shown in Figure 2. 'The RTML is equipped with apparatus and equipment to prepare soil, smear, and air filter samples for analysis and analyze these samples for low-level concentrations of alpha and gamma-emitting radionuclides. It is also equipped with four alpha CAMs that continuously monitor air for alpha-emitting TRU isotopes at locations up to $200 \mathrm{~m}$ from the RTML. Soil samples are not pretreated chemically prior to analysis but rather are dried and sieved before they are analyzed using spectrometric methods. Smear and air filter samples require no pretreatment.

The RTML consists of two separate mobile trailers that can be powered from either plant power or from portable electric generators. One trailer, $2.4-\mathrm{m}$ wide $\times 7.3-\mathrm{m}$ long $(8 \times 24 \mathrm{ft})$, houses the sample preparation laboratory that is equipped with a fume hood, fume hood HEPA filter, gravityflow drying oven, sieving equipment, analytical balances, compressed air cylinders, hotplates, and a supply of sample planchets and containers. Samples are received and prepared for analysis in this trailer. If plant power is unavailable, power to the sample preparation trailer is supplied from a $50 \mathrm{~kW}$ or larger generator. The second trailer, $2.4-\mathrm{m}$ wide $\times 14.6-\mathrm{m}$ long $(8 \times 48 \mathrm{ft})$, houses the analytical instruments and computer used to acquire, analyze, and archive photon and alpha spectra from soil, smear, and air filter samples. The latter trailer also houses the computer terminal used to remotely control the operation of the four field-deployable alpha CAMs. If plant power is unavailable, power to the analysis trailer is supplied from a generator rated at $30 \mathrm{~kW}$ or more, and power to the alpha CAMs is supplied from a $5 \mathrm{~kW}$ or larger generator.

Soil samples for the large-area, ionization chamber alpha spectrometers are dried, sieved, ground in $30 \%$ ethanol, and then sprayed onto $25.4-\mathrm{cm}$ diameter, stainless steel sample pans. These sample pans are transported from the sample preparation trailer to the analysis trailer inside six-sided plastic boxes. Each steel pan is held in place by grooves on the left and right walls of the box. The front wall of the box slides up to provide easy access to the sample pans and slides down to seal the box. Each box holds up to 20 sample pans.

Soil samples for the photon analysis spectrometer are dried and sieved. Eleven grams of the sieved soil is sealed inside a plastic planchet $70-\mathrm{mm}$ in diameter $\times 8-\mathrm{mm}$ thick. The sealed planchets are transported from the sample preparation trailer to the analysis trailer inside rectangular-shaped, metal sample magazines that were provided with the automatic sample changer. Each of the five sample magazines holds up to twenty $70 \times 8 \mathrm{~mm}$ planchets. 


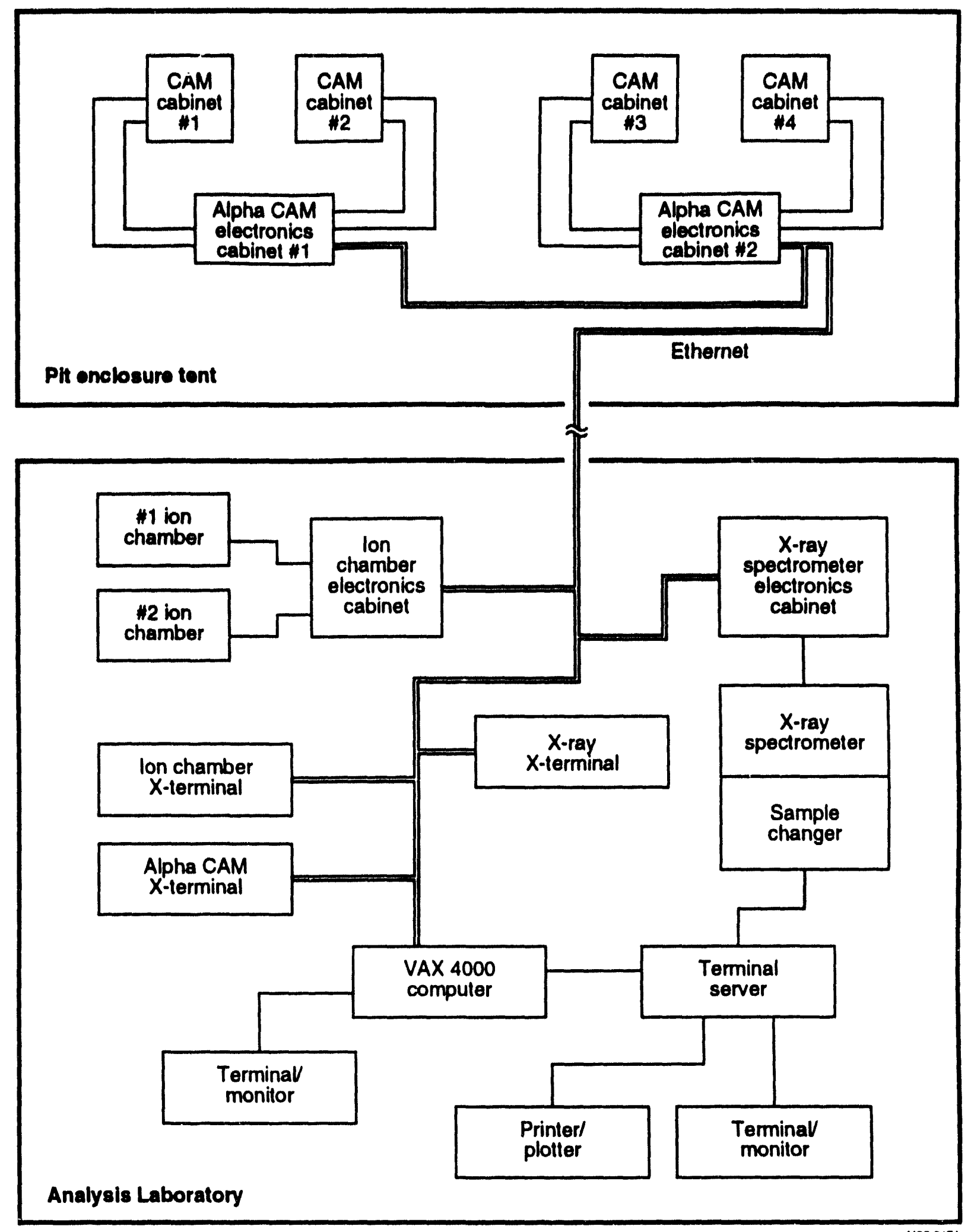

Y03 0171

Figure 2. Block diagram of RTML electronics. 
The general arrangement of the three RTML measurement systems is similar to the arrangement shown in Figure 2. The six alpha CAM sampling and electronics cabinets are located outside the RTML trailers and are connected to the VAX $\mathbf{4 0 0 0}$ via a thin-wire Ethernet cable. The two ionization chambers, their associated electronics, X-terminal, and monitor are located on a bench top near the rear of the analysis trailer. The extended-range germanium detector is positioned inside a sample changer located near the middle of the analysis trailer, between the rear bench and the forward bench. The electronics for the photon spectrometer are located inside an electronics cabinet that is adjacent to the sample changer. The X-terminal and monitor for the photon spectrometer are positioned on the forward bench top near the electronics cabinet. The X-terminal for the alpha CAM system is located on the forward bench top about $2 \mathrm{~m}$ from the photon spectrometer $X$ terminal. The VAX 4000 is located on the forward bench top at the front of the analysis trailer.

The three RTML measurement systems were operated separately in different laboratories at TRA before they were installed in the RTML analysis trailer. Placing the three systems inside the RTML analysis trailer as previously described did not adversely affect the performance of the systems. In the case of the ionization chambers, their performance in the trailer actually improved because the concentrations of radon daughters in the air inside the trailer were much lower than inside the laboratories at TRA.

\subsection{Sample Preparation Equipment}

The materials and equipment that are normally stored in the sample preparation trailer include

- Aluminum sample pan (6-1/2 in. square $\times 1-1 / 4$ in. deep)

200 ea

- Drying oven (Fisher Scientific, model 655G)

1 ea

- USA standard testing sieve, No. 50 (Fisher Scientific)

4 ea

- Sieve shaker (CSC Scientific Co., model 18480-033)

1 ea

- Polyethylene funnel

1 ea

- 2-oz polypropylene or polyethylene wide-mouth bottle

200 ea

- Sample tray for 2-oz bottle

5 ea

- 4-gal polyethylene bucket

- Analytical balance (Mettler AE200S)

1 ea

- 70-mm diameter $\times 8$-mm thick sample container

2 ea

- 25.4-cm diameter stainless steel sample pan

500 ea

- Mortar

50 ea

- Pestle

2 ea

- 20-mL graduated cylinder

2 ea

- $30 \%$ ethanol in $500-\mathrm{mL}$ squeeze bottle

2 ea

- Plunger-type pipette

2 ea

- Pipette tip

2 ea

50 ea 
- 10-mL, all-glass, air-operated hand sprayer (Kontes) 4 ea

- Compressed air cylinder 2 ea

- Compressed air cylinder regulator 2 ea

- Hotplate (Thermolyne Corp.) 2 ea

- Container for 25.4-cm diameter sample pans 4 ea

- Deionized water in $500-\mathrm{mL}$ squeeze bottle 2 ea

\subsection{Analytical Instruments}

\subsubsection{Beta Detectors}

- PNL's large-area beta detector 1 ea

- INEL's large-area, scintillation beta detector 1 ea

\subsubsection{Large-area Ionization Chamber Alpha Spectrometers}

The main components of the two existing large-area, ionization chamber alpha spectrometers are as follows.

- Ionization chamber (Ordela, Inc., model 8200A) 1 ea

- Preamplifier (Ordela, Inc., model 8200A) 1 ea

- Ionization chamber (Ordela, Inc., model 8210A) 1 ea

- Preamplifier (Ordela, Inc., model 8210A) 1 ea

- Vacuum gauge (Matheson) 2 ea

- Pressure switch for bias voltage 2 ea

- Vacuum pump (Leybold-Heraeus, model D2A) 1 ea

- Cylinder P-10 gas 1 ea

- Two-stage gas cylinder regulator (Victor Equip. Co., VTS452D) 1 ea

- High-voltage bias supply (Bertan, model 355) 1 ea

- High-voltage bias supply (ORTEC, model 459) 1 ea

- Amplifier (Canberra, model 2021) 1 ea

- Amplifier (Canberra, model 2020) 1 ea

- Analog-to-digital (ADC) (Canberra, model 8713) 2 ea

- Acquisition interface module (AIM) (ND 556) 1 ea

- Nuclear instrument module (NIM) bin (ORTEC 401A) 1 ea

- NIM bin (Tennelec TB3/TC911-6 TURBO) 1 ea

- X-terminal (NCD 88K) 1 ea

- X-terminal monitor (NCD19c) 1 ea

\subsubsection{Photon Analysis Spectrometer System}

The main components of the photon analysis spectrometer system are as follows. 
- Thin-window germanium detector (PGT NIGC 2830) 1 ea

- Preamplifier (PGT RG11B/C) 1 ea

- Dual-energy pulsar (EG\&G Idaho) 1 ea

- 30-L liquid nitrogen dewar (EG\&G ORTEC) 1 ea

- Sample changer (Gamma Products, Inc., model G3200) 1 ea

- Sample changer controller (Gamma Products, Inc., model G6200) 1 ea

- Electronics cabinet 1 ea

- High-voltage bias supply (PGT, model 315A) 1 ea

- Amplifier (Tennelec, model TC245) 1 ea

- ADC (ND 581) 1 ea

- $\quad$ AIM (ND 556) $\quad 1$ ea

- NIM bin (Tennelec TB3/TC911-6 TURBO) 1 ea

- X-terminal (NCD 88K) 1 ea

- X-terminal monitor (NCD19c) 1 ea

- Personal computer (DTK Computer, Inc., model PEEK-2533) 1 ea

- Personal computer monitor (Packard Bell, model PB8539VG) 1 ea

\subsubsection{Alpha Continuous Air Monitors}

The main components of each alpha CAM sampling cabinet and electronics cabinet are as follows.

Sampling cabinet:

- Solid-state heater/air conditioner (TECA, model AHP-301FFHC) 1 ea

- Two-stage inertial impactor 1 ea

- Passivated implanted planar silicon (PIPS) detector (Canberra, model PD-900-27-100-AM or CAM 900AM) 1 ea

- Preamplifier (Canberra, model 2003BT) 1 ea

- Mass flow meter (Sicrra Instr., ACCU-MASS, model 730-12V) 1 ea

- Mass flow meter (McMillan Co., model 100-11) 1 ea

- Vacuum pump (Gast, model 1031-102A-351X) 1 ea

- 5-stage blower (AMETEK, model 116246-00) 1 ea

- Power strip 1 ea

- Power cord $150 \mathrm{ft}$

Electronics cabinet:

- Solid-state air conditioner (TECA, model AHP-1200X) 1 ea

- Bias supply (EG\&G ORTEC 659) 2 ea

- Amplifier (EG\&G ORTEC 572) 2 ea

- ADC (Canberra, model 8701) 2 ea

- Multiplexer (Canberra AMX, model 8224) 2 ea 
- AIM (ND 556)

1 ea

- NIM bin (Tennelec TB3/TC911-6 TURBO) 1 ea

- Power strip 1 ea

- Power cord $150 \mathrm{ft}$

Specifications for the detectors and electronic equipment purchased from commercial vendors are given in the instruction manuals, operating and service manuals, calibration and NIST certification sheets, and product catalogs provided by the vendors. Specifications data for RTML equipment are not included in this test plan because they are too voluminous. They are currently kept by the PIs but will be collated and placed in the RTML analysis trailer in the near future.

\subsection{Calibration Procedures}

Calibration measurements are performed prior to instrument operation if the instrument has been out of service. During routine operation calibration measurements are performed daily.

\subsubsection{Beta Detectors}

The absolute counting efficiency of each beta detector is determined and checked by measuring soil and smear standards containing known quantities of ${ }^{90} \mathrm{Sr}$ in equilibrium with ${ }^{90} \mathrm{Y}$.

\subsubsection{Large-area Ionization Chamber Alpha Spectrometers}

Calibration standards containing three radionuclides having principal alpha energies as widely separated as possible are used to adjust the energy calit stion and to determine the linearity of response. The radionuclides used are ${ }^{230} \mathrm{Th},{ }^{239} \mathrm{Pu}$, and ${ }^{244} \mathrm{Cm}$, which emit alpha particles having average alpha energies of $4,684,5,155$, and $5,805 \mathrm{keV}$, respectively. The activity of each radionuclide is sufficient to give excellent counting statistics in a 10-minute count. The gain and digital offset will be maintained to keep the three alpha peaks in their desired channel positions. The analyzer has been set to cover 512 channels at $10 \mathrm{keV}$ per channel beginning at $2,800 \mathrm{keV}$, so that the alpha peak of the principal radon daughter ${ }^{214} \mathrm{Po}$ at $7,687 \mathrm{keV}$ is displayed at the higher energy end of the spectrum while providing as much space as possible at the lower energy end to accommodate degraded pulses.

\subsubsection{Photon Analysis Spectrometer System}

The following calibrations will be performed using the following procedures and programs. If instabilities or other unanticipated problems arise, the spectrometer will be recalibrated as necessary.

The energy scale for the entire energy region is determined from the pulsar, which is calibrated against a special radioactive source comprised of ${ }^{57} \mathrm{Co},{ }^{137} \mathrm{Cs}$, and ${ }^{60} \mathrm{Co}$ using the XCALIB program. Since two different analysis programs are used to analyze the $\mathrm{L} x$-ray and gamma-ray energy regions 
of each spectrum, the spectrometer requires two separate and distinct radionuclide activity calibrations.

The spectrometer is calibrated for $\mathrm{Pu}$ and ${ }^{241} \mathrm{Am}$ by counting standards containing known quantities of these radionuclides. The COMPONENT program subtracts the background from each component of the spectrum, corrects for the sample mass or volume, and scales each component to a fixed disintegration rate. When an unknown sample is analyzed, the $\mathrm{L}$ x-ray portion of the spectrum is fit to the components of the calibration spectra using linear least squares methods. A standardization coefficient relates the relative magnitudes of the standard component with that of the unknown sample. The standardization coefficient is then scaled by the mass or volume of the sample and the count time to yield the sample activity or activity concentration.

With one exception. the gamma-ray energy region from about 59 to $1,350 \mathrm{keV}$ is calibrated following the same procedure as is normally used for germanium gamma-ray detectors. A special mixed radionuclide calibration source is used that contains ${ }^{54} \mathrm{Mn}$ and ${ }^{65} \mathrm{Zn}$ in addition to ${ }^{241} \mathrm{Am},{ }^{109} \mathrm{Cd}$, ${ }^{57} \mathrm{Co},{ }^{139} \mathrm{Ce},{ }^{203} \mathrm{Hg},{ }^{113} \mathrm{Sn},{ }^{137} \mathrm{Cs},{ }^{88} \mathrm{Y}$, and ${ }^{60} \mathrm{Co}$. This mix was chosen because most of the gamma-rays emitted by this mix are relatively free of cascade coincidence summing. Since the gamma-rays from ${ }^{88} \mathrm{Y}$ and ${ }^{60} \mathrm{Co}$ are in cascade, these gamma-rays are not included in the efficiency measurements but can be used to estimate the amount of coincidence summing occurring with other radionuclides having gamma-rays with energies above $800 \mathrm{keV}$. An efficiency curve from 50 to $1,400 \mathrm{keV}$ is developed using an efficiency measurement program developed for use by the RML at the INEL.

\subsubsection{Alpha Continuous Air Monitors}

The energy calibration of each solid-state silicon detector is determined and intermittently checked by measuring a filter standard that contains ${ }^{230} \mathrm{Th},{ }^{239} \mathrm{Pu}$, and ${ }^{244} \mathrm{Cm}$. The three isotopes emit alpha particles having average energies of $4.684,5.155$, and $5.805 \mathrm{Mev}$, respectively. The absolute counting efficiency of each alpha detector is determined and checked by measuring either the same filter standard used to perform energy calibrations or filter standards that contain known quantities of ${ }^{239} \mathrm{Pu}$. The latter standards were prepared using membrane filters having a pore size of $0.1 \mu \mathrm{m}$. The ${ }^{239} \mathrm{Pu}$ activity was transferred to the filters using a neodymium fluoride carrier in dilute perchloric acid. The method has been shown to provide an even distribution of activity over a filter surface with minimal loss of alpha particle energy. The quantity of material deposited on the filter standards is about $30 \mu \mathrm{g} / \mathrm{cm}^{2}$.

\subsection{Maintenance and Operation}

RTML equipment will be maintained and operated according to RTML operating procedures. The dewar of the germanium spectrometer will be filled with liquid nitrogen twice a week while the spectrometer is in use. 


\subsection{Sensitivity to Environmental Conditions}

The analytical instruments installed in the RTML are designed to operate under normal laboratory conditions of temperature, humidity, and airborne dust loading. The electronics are designed to operate over the temperature range 0 to $50^{\circ} \mathrm{C}\left(32\right.$ to $\left.122^{\circ} \mathrm{F}\right)$. High levels of mechanical vibration and acoustic noise in the vicinity of the photon analysis spectrometer and large-area, ionization chamber alpha spectrometers can generate undesirable microphonic noise in the spectral data. To minimize the effect of vibrations and acoustic noise, the extended-range germanium detector and ionization chambers are installed on rubber or foam pads. The spectral resolutions and sensitivities of the four RTML alpha CAMs are significantly degraded when airborne dust concentrations are above about $10 \mu \mathrm{g} / \mathrm{L}$. 


\section{SUPPLIES, UTILITIES, AND FACILITIES}

Office and laboratory facilities and utilities at TRA will be used. When the mobile laboratory is in the field, trailer power will be supplied by diesel generators. 


\section{HEALTH AND SAFETY}

Safety is of utmost concern with all experiments. It is the policy of EG\&G Idaho to take every practical precaution to guard the health and safety of its employees and the general public. Three types of safety concerns are emphasized: radiological, laboratory, and waste management. Standard practices for each of these three areas are described in the company and/or group standard practices manuals that are identified in the following three sections.

\subsection{Radiological Safety}

Radiological safety and conformance to the EG\&G Idaho Radiological Controls Manual (RADCON Manual) will be ensured by consulting on-duty RADCON personnel before beginning work involving radioactive materials. Subsections of the manual that apply to this document include

Chapter 3, "Airborne Radioactivity Limits, HEPA Filter Requirements, Monitoring for Airborne Radioactivity"

Chapter 4, "Enclosure for Containing Contamination and Severe Measurements"

Chapter 8, "Constant Air Monitors, Instrument Calibration and Control, Selection and Installation of Continuous Air Monitors"

Chapter 11, "Continuous Availability of RADCON Personnel, Inspecting Radiological Work, Planning Radiological Controls, Radiation Worker Training, Radiological Controls, Review and Approval."

The radioactive samples being assayed consist of small quantities of soil $(<25 \mathrm{~g})$, smears $(47-\mathrm{mm}$ diameter filter paper), and CAM filters that are contained within a 70 -mm diameter $\times 8$-mm thick plastic container with a snap-on lid. Typical activities or activity concentrations are $<1,100 \mathrm{pCi} / \mathrm{g}$ and $<5,000 \mathrm{pCi}$, respectively. Therefore, the radiological hazard is small and consists in potential contamination by low activity radioactive material and the possibility of a high activity sample not being identified by the upstream screening performed with portable health physics (HP) instrumentation.

1. Hazards

a. Exposure by a high activity sample not identified by upstream monitoring with HP instrumentation.

b. Spread of low activity radioactive material due to leakage or by unsealed or broken containers. 


\section{Precautions}

a. All samples will be monitored by HP instrumentation before released from the sample preparation trailer to be counted in the mobile laboratory trailer.

b. Samples will be sealed with sealant (e.g., super glue, RTV, or model airplane glue) or with transparent tape before handling. Prepared samples will be promptly loaded into the sample holder for most handling operations and will not be removed until all counting is complete.

c. The sample magazine shall always be held at an upward angle to prevent individual samples from sliding out of the sample holder magazine.

\subsection{Laboratory Safety}

Laboratory safe practices are described in the Science and Technology Standard Practices Manual, Section 2. Subsections that apply to this document in Section 2.1, "General Laboratory Practices," include

2.1.5, "Eye Protection and Protective Clothing"

2.1.6, "Laboratory Safety"

2.1.8, "Laboratory Hood Use."

Subsections that apply to Section 2.2, "Site Laboratory Practices," include

2.2.4, "Radioactive Materials Handling"

2.2.7, "Laboratory Radiological Training."

The photon analysis spectrometer uses a liquid nitrogen (LN) cooled germanium spectrometer. The dewar that maintains the detector at LN temperatures is filled weekly, or when the operation requires, twice a week.

1. Hazards

a. Asphyxiation, if $\mathrm{LN}$ evaporates rapidly in a confined space. This is a remote possibility even when dewars develop a vacuum leak.

b. Burns, if LN gets on tight fitting clothing, is trapped in shoes or pockets, or gets on bare skin.

c. Explosion, if $\mathrm{LN}$ is confined without pressure relief. 


\section{Precautions}

a. Protective equipment should be worn including leather or cryogenic gloves and goggles

b. Piping and transfer lines should be constructed to avoid trapping $L N$ in the lines

c. LN should be vented to a well ventilated room or to the outside whenever possible, or an oxygen depletion monitor should be used when ventilation is not adequate.

No electric circuits are exposed to the operator and most of the instrumentation operates on $+12,-12$, and $-24 \mathrm{~V}$ circuits. Therefore, use of frayed cords or careless operations such as operation with wet hands or unauthorized repairs, could result in electrical shock.

\section{Hazards}
a. Frayed power cords
b. Operation with wet hands

2. Precautions

a. Before every campaign or on the first day of each month that the photon analysis spectrometer is used, power cords should be checked for fraying especially near the electrical plug.

b. System should be operated with dry hands only.

Although no heavy lifting or extended reaching is involved in preparing or counting samples, various common physical hazards potentially exist. Most of these hazards are encountered in the sample preparation trailer and include cuts from sharp objects and burns from touching objects that were heated in the drying oven; however, eye strain, repetitive motions (carpal tunnel syndrome), and tripping hazards are also subtle concerns. Personnel involved in the in-field test demonstration should also be cautious of these hazards and take measures to avoid them. Personnel should exercise good office safety.

\section{Hazards}
a. High temperature
b. Sharp edges
c. Eye strain and repetitive motions 


\section{Precautions}

a. Handle heated objects with tongs or gloves.

b. Beware of any sharp objects that could inflict a wound.

c. Take 10-minute breaks from the computer console every hour.

\subsection{Waste Menagement Practices}

Waste management practices are prescribed in the EG\&G Idaho Safety Manual, Section 15, and the Science and Technology Standard Practices Manual, Section 2. Pertinent sections include

2.1.1, "Nonradioactive Chemical Waste Disposal"

2.1.3, "Chemical Lab Inventory"

2.1.4, "Chemical Spill Control"

and

2, "Incinerable Low-level Radioactive Waste"

3, "Compactible Low-level Radioactive Waste"

9. "Transuranic Waste"

15.1, "Routine Solid Waste Collection and Handling." 


\section{RESIDUALS MANAGEMENT}

No radioactive waste will be generated in the RTML since all radioactive standards will be prepared in permanent chemistry laboratories at TRA. Those wastes will be disposed of according to standard practices listed in Section 12. The radioactive standards will be archived for future use and will remain under the custodianship of the PIs or the work leader of the RML at TRA. Cold waste generated in th: RTML will be disposed of using common cold waste disposal practices. Laboratory equipment installed or stored in the RTML will remain in the RTML following completion of the FY-94 work. 


\section{REFERENCES}

1. C. V. McIsaac, et al., Operating Procedures for Rapid Transuranic Monitoring Laboratory, EG\&G Idaho, Inc., EG\&G-WTD-10898, October 1993.

2. C. V. Mclsaac, et al., Field Test of the Rapid Transuranic Monitoring Laboratory, EG\&G Idaho, Inc., EG\&G-WTD-10935, December 1993.

3. A. J. Schilk, et al., Surface and Subsurface Characterization of Uranium Contamination at the Femald Environmental Management Site, Pacific Northwest Laburatories, PNL-8617, April 1993.

4. L. C. Rounds and J. K. McDonald, Buried Waste Integrated Demonstration Technology Test Plan Guidance, EG\&G Idaho, Inc., EGG-WTD-9800, Rev. 1, January 1994.

5. L. A. Currie, "Limits for Qualitative Detection and Qualitative Determination," Anal Chem 40:586593, 1968. 


\section{Appendix A}

Full-scale Operation Estimates

A-1 


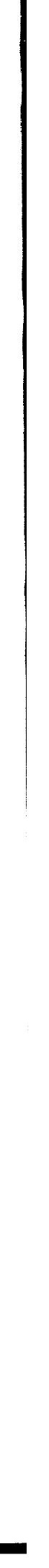




\section{Appendix A}

\section{Full-scale Operation Estimates}

a. Operation and maintenance cost for the life cycle of the technology is demonstrated. Operation and maintenance cost includes storage and disposition of waste, operation of equipment (e.g., labor and electrical power), maintenance (e.g., cost of replacement parts and labor), and decommissioning.

Unknown.

b. Acquisition cost, including capital.

Approximately $\$ 500,000$.

c. Volume $\left(\mathrm{m}^{3}\right)$ of input material, toxicity level, mobility, and physical state.

Not applicable.

d. Volume $\left(\mathrm{m}^{3}\right)$ of contaminated material produced (e.g, gloves, bags, tools, and process water) and physical state.

Unknown.

e. Time to remediate the input volume.

Not applicable.

f. Time to remediate $50 \%$ of the input volume.

Not applicable.

g. List the process output, their waste classification, concentration or activity, toxicity level, mobility, and volume $\left(\mathrm{m}^{3}\right)$.

Not applicable. 
h. Time until (a) line item and capital equipment replacement costs exceed $50 \%$ of acquisition cost and (b) line item and capital equipment repair and maintenance costs are estimated to approach $50 \%$ of acquisition costs. Compare to expected useful life (see item a above).

\section{Unknown.}

i. Assemblies and subassemblies specified in the design and functional operating requirements. and longest procurement lead times for custom and engineered components.

See sections 10.2 and 10.3. The longest procurement lead times is about 60 days.

j. Total number of custom assemblies and subassemblies.

The only equipment not commercially available is the dual-energy pulsar used with the photon analysis spectrometer. The pulsar is built by EG\&G Idaho, Inc.

k. Time for scheduled maintenance.

\section{Unknown.}

1. Time for unscheduled maintenance.

\section{Unknown.}

m. Time from now to field demonstration. Now is considered to be the approval date of the technical evaluation report.

The RTML was demonstrated at the Cold Test Pit at the INEL in June 1993.

n. Time from now until full-scale operation.

Unknown.

o. Mean years of specialized training required for full-scale operation (academic and facility specific).

\section{Unknown.}

p. Labor hours per hour of operation.

Two to four depending on the sample load. 
q. Time for replacement parts to exceed $50 \%$ of the acquisition costs.

Unknown.

r. The list of permits required for a full-scale operation.

\section{Unknown.}

s. Time to construct or fabricate the equipment necessary to operate the process.

The RTML could be duplicated in 6 months.

t. Types and quantities of utilities (e.g., water and electricity) required during the process.

$80 \mathrm{~kW}, 240 \mathrm{~V}$, single-phase and $5 \mathrm{~kW}, 120 \mathrm{~V}$, single-phase.

u. Time to train technical personnel and operators.

One month.

v. Extra time and costs prudently estimated to cover contingencies (i.e., unplanned events outside the control of the principal investigator and the Buried Waste Integrated Program).

Unknown. 
Appendix B

\section{CERCLA Criteria}

B-1 
$-2$ 


\section{Appendix B}

\section{CERCLA Criteria}

1. Overall Protection of Human Health and the Environment-This assessment determines whether the alternative can adequately protect human health and the environment, in both the short and long term, from unacceptable risks.

Not known.

2. Compliance with Applicable or Relevant and Appropriate Requirement-This assessment determines whether the alternative can attain applicable or relevant and appropriate requirements under Federal environmental laws and state environmental or facility siting laws or provide grounds for invoking a waiver.

Not known.

3. Long-Term Effectiveness and Permanence-This assessment determines the long-term effectiveness and permanence that the alternative affords, along with the degree of certainty that the alternative will prove successful.

Not known.

4. Reduction of Toxicity, Mobility, and Volume Through Treatment-This assessment determines the degree to which the alternative employs recycling or treatment that reduces toxicity, mobility, or volume and includes how treatment is used to address the principal threats posed by the site.

Not applicable.

5. Short-Term Effectiveness-This assessment determines the short-term impacts of the alternatives.

Not known.

6. Implementability-This assessment identifies the ease or difficulty of implementing the alternative.

Not known. 
7. Cost-This assessment identifies capital costs, including both direct and indirect, annual operation and maintenance costs, and net present value of capital and Operation and Maintenance costs.

Capital cost to duplicate the Rapid Transuranic Monitoring Laboratory is about $\$ 500,000$. Other costs are not known.

8. State Acceptance-This is an assessment of state concerns and may not be completed until comments on the Remedial Investigation/Feasibility Study are received but may be discussed, to the extent possible.

Not known.

9. Community Acceptance-This assessment includes determining which components of the alternative interested persons in the community support, have reservations about, or oppose.

Not known. 

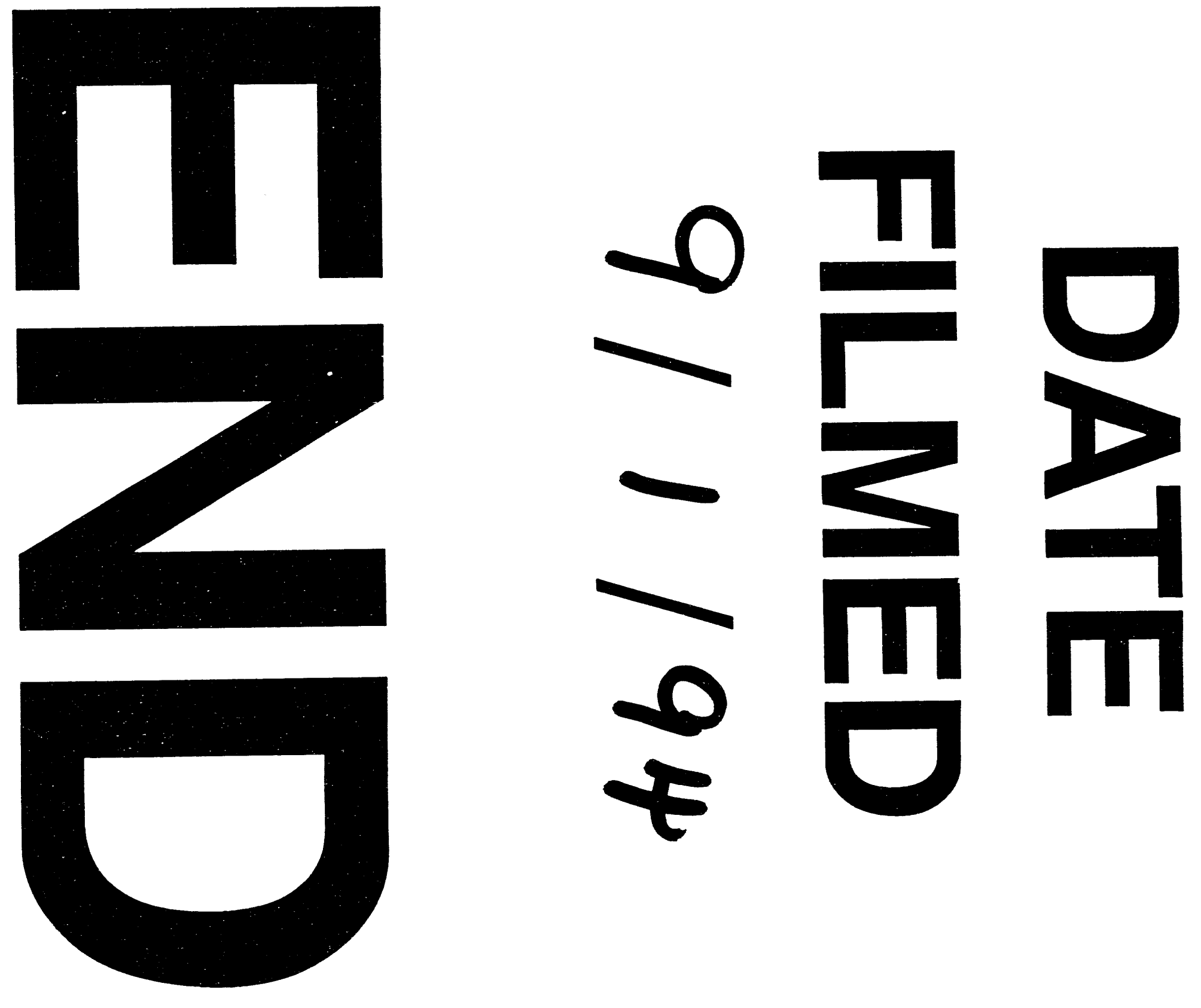


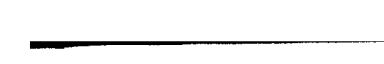

